\title{
Modeling analysis of the seasonal characteristics of haze formation in Beijing
}

\author{
X. Han ${ }^{1}$, M. Zhang ${ }^{1}$, J. Gao ${ }^{2}$, S. Wang ${ }^{2}$, and F. Chai ${ }^{2}$ \\ ${ }^{1}$ State Key Laboratory of Atmospheric Boundary Layer Physics and Atmospheric Chemistry, Institute of Atmospheric \\ Physics, Chinese Academy of Sciences, Beijing, China \\ ${ }^{2}$ Chinese Research Academy of Environmental Sciences, Beijing, China
}

Correspondence to: M. Zhang (mgzhang@mail.iap.ac.cn)

Received: 14 October 2013 - Published in Atmos. Chem. Phys. Discuss.: 21 November 2013

Revised: 19 August 2014 - Accepted: 20 August 2014 - Published: 25 September 2014

\begin{abstract}
The air quality modeling system RAMS-CMAQ (Regional Atmospheric Modeling System-Community Multiscale Air Quality), coupled with an aerosol optical property scheme, was applied to simulate the meteorological field, major aerosol components (sulfate, nitrate, ammonium, black carbon, organic carbon, dust, and sea salt), and surface visibility over the North China Plain (NCP) in 2011. The modeled results in February and July 2011 were selected and analyzed to obtain an in-depth understanding of the haze formation mechanism in Beijing for different seasons. The simulation results showed that the visibility was below $10 \mathrm{~km}$ for most regions of the NCP, and dropped to less than $5 \mathrm{~km}$ over the megacities of Beijing and Tianjin, the whole of Hebei Province, and the northwest part of Shandong Province during pollution episodes in February and July. The heavy mass concentration of $\mathrm{PM}_{2.5}$ ranged from 120 to $300 \mu \mathrm{g} \mathrm{m}^{-3}$ and was concentrated in the areas with low visibility. The haze formation mechanism in Beijing in winter was different from that in summer. The mass concentration of $\mathrm{PM}_{2.5}$ was higher, and the components more complicated, in winter. While the mass concentration of $\mathrm{PM}_{2.5}$ in summer was lower than that in winter, the mass concentrations of hygroscopic inorganic salts were comparable with those in winter, and the relative humidity was, as expected, higher. Therefore, the water uptake of hygroscopic aerosols played a key role in summer. Moreover, the analysis showed that the influence of the $\mathrm{PM}_{2.5}$ mass burden on visibility was very weak when its value was larger than $100 \mu \mathrm{g} \mathrm{m}^{-3}$. Only when the mass burden of $\mathrm{PM}_{2.5}$ decreased to a certain threshold interval did the visibility increase rapidly. This indicates that, when emission reduction measures are taken to control
\end{abstract}

haze occurrence, the mass burden of $\mathrm{PM}_{2.5}$ must be cut to below this threshold interval. The relationship between the threshold of haze occurrence and the relative humidity in Beijing was fitted by an exponential function, and the resulting fitting curves could provide a new theoretical basis to understand and control haze formation in Beijing.

\section{Introduction}

The emission of air pollutants have increased significantly because of the economic growth, rapid population expansion, and urbanization in the North China Plain (NCP). Beijing has a population of over 20 million and is the political, economic, and cultural center of China, of which it is also the capital. This megacity is located at the northern tip of the $\mathrm{NCP}$ and surrounded by high mountains in its northern and western boundaries. Beijing has suffered from air quality deterioration in the past decade because of strong local emissions (Sun et al., 2006) and long-range transport from the surrounding urban areas (Zhang et al., 2012) to the east and south of the NCP; such areas include Tianjin, Shijiazhuang, and a number of cities where economic development is most active in Hebei Province. The air pollution in Beijing is easily aggravated by its special geographic position when stable weather appears or the south wind dominates. Although the $\mathrm{SO}_{2}$ emission in Beijing in the last 5 years has been decreased by various measures prescribed by the current legislation on emission controls (Lu et al., 2010; Zhang et al., 2006), the mass burden of particulate pollutants remains at 
a high level (Hao et al., 2012; Zhang et al., 2013), causing serious environmental issues and associated health effects.

Atmospheric haze is caused by visibility deterioration to less than $10 \mathrm{~km}$ when the relative humidity does not exceed $90 \%$ (Wu et al., 2007) through light extinction by aerosol particles. As a result of the high level of aerosol loadings, widespread haze cloud caused by serious air pollution has occurred more frequently over this region in the past decade (Ma et al., 2010; Tao et al., 2012; Wang et al., 2013; Zhao, et al., 2011). A number of studies have investigated the longterm variation features of haze days in Beijing and the NCP. Quan et al. (2011) collected monitoring data and summarized the haze day occurrence trend over the NCP for the past 56 years. They also analyzed the effect of high aerosol loadings on haze formation by conducting a field measurement campaign and found the important role for hygroscopic growth of aerosols during the haze period. Yu et al. (2011) analyzed aerosol optical properties during haze days in the past 7 years and compared the features of single-scattering albedo and asymmetry factors during haze days with those during dust days in Beijing. This study also found that fine-mode particles were dominant in aerosol size distributions during haze days.

Numerous methods have been used to investigate the chemical and physical properties of aerosols during haze occurrences in Beijing in different seasons. Li et al. (2013) identified the aerosol size distribution and chemical composition from ground-based remote sensing measurements during haze days in winter. Li et al. (2010) detected the aerosol components by using transmission electron microscopy with energy-dispersive X-ray spectrometry during a haze episode in summer and determined the influence of carbonaceous aerosols. Liu et al. (2013) and Zhao et al. (2013) conducted intensive field experiments to identify the aerosol components of fine particles and discussed the constituent features of $\mathrm{PM}_{2.5}$ during the haze periods in autumn and winter, respectively. Wang et al. (2006) compared the characteristics of aerosol components during dust, haze, and clean days. These previous works have provided abundant information on the physical and chemical properties of aerosols during haze days. However, the complex mechanism of haze formation over Beijing and its surrounding regions requires further study. Various influencing factors - including the meteorological field, key aerosol components, and microphysical properties - should be comprehensively considered in investigating the relationship between aerosols and surface visibility. Moreover, the seasonal similarities and differences of the haze formation mechanism in Beijing remain unclear because most of these studies were generally focused on the pollution periods in the same season.

In the present study, an air quality modeling system called the Regional Atmospheric Modeling System-Community Multiscale Air Quality (RAMS-CMAQ) coupled with an aerosol optical property scheme was applied to simulate the meteorological field, the mass burden of the major aerosol components (sulfate, nitrate, ammonium, black carbon (BC), organic carbon (OC), dust, and sea salt), and the surface visibility over the NCP in 2011. The simulation results in February and July 2011 were selected for analysis. This study aims to discuss the contributions of various influencing factors to visibility deterioration and to compare the differences of the winter and summer haze formation mechanisms.

\section{Methodology}

The air quality modeling system RAMS-CMAQ was applied to concurrently simulate the atmospheric and land processes that affect the transport, transformation, and deposition of aerosols and their precursors. The major component of this modeling system was CMAQ (version 4.7), developed by the US Environmental Protection Agency for assessing the effect of multiple pollutants, including tropospheric ozone and other oxidants, aerosols, and acid deposition (Byun and Schere, 2006; Eder and Yu, 2006; Eder et al., 2009; Mathur et al., 2008). The gas-phase chemistry mechanism was updated to the expanded version CB05 (Sarwar et al., 2008). The thermodynamic equilibrium between inorganic aerosol species and gas-phase concentrations was treated by ISORROPIA (Nenes et al., 1999). The Regional Particulate Model (Binkowski and Shankar, 1995) was used to describe the processes of aerosol dynamics in CMAQ; such processes include new particle production, coagulation, and condensation (Bhave et al., 2004; Yu et al., 2013). The formation of secondary organic aerosol (SOA) was mainly treated by the CB05 mechanism, which was extended to allow for production of SOA from anthropogenic and biogenic precursors. In CB05, the SOA formation was modeled by forming semivolatile products in volatile organic compounds' (VOCs) reactions. The semi-volatile products were partitioned between the gas and aerosol phase according to the ambient conditions, such as temperature, relative humidity, vapor pressure, and existing aerosol particles. The aerosol particles in the modeling system were divided into three modes, namely, Aitken, accumulation, and coarse modes (dust and sea salt). All modes were assumed to follow the lognormal distribution. The aerosol components, the geometric standard deviation, and the geometric mean radius of each mode are listed in Table 1. The numerical prediction model RAMS was coupled with CMAQ in the offline method to provide CMAQ with a meteorological field. A general description of RAMS and its capabilities has been provided by Cotton et al. (2003). RAMS can describe the boundary layer and the underlying surface effect, which is important for capturing air pollutants and haze occurrence. The background meteorological fields and sea surface temperature were obtained from the European Centre for Medium-Range Weather Forecasts reanalysis data sets $\left(1^{\circ} \times 1^{\circ}\right.$ spatial resolution) and were based on weekly mean values and observed monthly snow cover information, respectively. 
Table 1. Aerosol size distribution parameters in RAMS-CMAQ.

\begin{tabular}{|c|c|c|c|}
\hline Mode & Aerosol components & $\sigma^{\mathrm{a}}$ & $r^{\mathrm{b}}, \mu \mathrm{m}$ \\
\hline Aitken & $\mathrm{ASO}^{\mathrm{c}}, \mathrm{ANO}^{\mathrm{d}}, \mathrm{ANH}^{\mathrm{e}}, \mathrm{BC}^{\mathrm{f}}, \mathrm{OC}^{\mathrm{g}}$ & 1.7 & 0.015 \\
\hline Accumulation & ASO4, ANO3, ANH4, BC, OC, dust, sea salt & 2.0 & 0.150 \\
\hline Coarse dust & Dust & 3.0 & 0.300 \\
\hline Coarse sea salt & Sea salt & 3.5 & 0.300 \\
\hline
\end{tabular}

The anthropogenic emissions of precursors and primary aerosols $\left(\mathrm{NO}_{\mathrm{x}}, \mathrm{SO}_{2}, \mathrm{VOCs}, \mathrm{BC}, \mathrm{OC}, \mathrm{PM}_{2.5}\right.$, and $\left.\mathrm{PM}_{10}\right)$ were obtained from the monthly-based emission inventory in China for 2010. This emission inventory has a spatial resolution of $0.25^{\circ} \times 0.25^{\circ}$ and included four categories, namely, power, industry, residential, and transport (Lu et al., 2011). The nitrogen oxides and ammonia from soil were adopted from the Global Emissions Inventory Activity $1^{\circ} \times 1^{\circ}$ monthly global inventory (Benkovitz et al., 1996). The monthly mean inventory of the Global Fire Emissions Database Version 2 (Randerson et al., 2007) was used to provide the biomass burning emissions from forest wildfires, savanna burning, and slash-and-burn agriculture. The online mechanisms introduced by Han et al. (2004) and Gong (2003) for capturing dust and sea salt emissions, respectively, were included in the modeling system.

A scheme of aerosol optical properties was added to the modeling system to estimate the aerosol extinction coefficient. This scheme contains a parameterization (Ghan and Zaveri, 2007) to efficiently simplify Mie theory calculation while maintaining sufficient accuracy. Briefly speaking, the lognormal distribution in each mode can be expressed as

$$
\frac{\mathrm{d} N}{\mathrm{~d} \ln D}=\frac{N}{(2 \pi)^{1 / 2} \ln \sigma_{\mathrm{g}}} \exp \left(-\frac{\left(\ln D-\ln D_{\mathrm{p}}\right)^{2}}{2 \ln ^{2} \sigma_{\mathrm{g}}}\right),
$$

where $N$ is the number concentration of aerosol particles, $\sigma_{\mathrm{g}}$ is the geometric standard deviation, $D$ is the particle diameter, and $D_{\mathrm{p}}$ is the geometric mean diameter. If the refractive index and $\sigma_{\mathrm{g}}$ are given and the $N$ is set as a normalized value, the aerosol optical properties can be calculated by Mie theory under several size distributions with different $D_{\mathrm{p}}$. The values of the specific optical properties under these size distributions can be fitted by the Chebyshev polynomials with just five fitting coefficients. Subsequently, the fitting coefficient table can be constructed with all possible values of refractive index and $\sigma_{\mathrm{g}}$. The scheme also applies Kohler theory (Pruppacher and Klett, 1997) and the Maxwell-Garnett mixing rule (Chuang et al., 2002) to describe the effects of water uptake and internal mixture, respectively. A detailed description of this scheme can be found in Han et al. (2011). The visibility can be obtained by using the following equation:

$\mathrm{VIS}=3.912 / \beta$, where VIS is the horizontal visibility, and $\beta$ is the aerosol extinction coefficient (Seinfeld and Pandis, 1998). This modeling system was used to simulate the mass concentration and optical properties of key aerosols in previous studies on aerosol effects on the climate and environment in China (Han et al., 2011, 2013; Zhang et al., 2005, 2006, 2007).

For the simulation over the NCP, a coarse domain covering most of East Asia with a horizontal grid distance of $64 \mathrm{~km}$ and a total area of $6654 \mathrm{~km} \times 5440 \mathrm{~km}$ with a twoway nested inner domain was established (Han et al., 2011). The inner domain (Fig. 1) had $94 \times 90$ grid cells and a $16 \mathrm{~km}$ resolution on a rotated polar stereographic map projection centered at $\left(116^{\circ} \mathrm{E}, 40^{\circ} \mathrm{N}\right)$. This domain included all major regions in the NCP, namely, the megacities of Beijing and Tianjin and Hebei, Shandong, and Shanxi provinces. A total of 15 vertical levels, nearly half of which were concentrated in the lowest $2 \mathrm{~km}$, were used to improve the simulation of the atmospheric boundary layer. The positions of the measurement stations applied to model evaluation are marked on Fig. 1, as are the district areas of four major cities: Beijing, Tianjin, Shijiazhuang, and Jinan.

\section{Model evaluation}

In this section, the model simulations are compared with the observations. Meteorological drivers are an important factor in aerosol and visibility simulation. The wind vector, temperature, and relative humidity are inherently related to aerosol transport, scavenging, and water uptake. Thus, the monitoring data from the surface stations of the Chinese National Meteorological Center (CNMC; http://cdc.cma.gov. $\mathrm{cn} /$ home.do) were collected to evaluate the performance of the meteorological field simulation. The CNMC has 726 measurement stations evenly distributed throughout mainland China, and has been providing long-term surface observations of several meteorological variables since 1 January 1951 (Feng et al., 2012).

The comparative results of the daily-average temperature, relative humidity, wind speed, and maximum wind direction at eight stations in February and July are shown in Figs. 2 to 5. The modeled temperature, relative humidity, and wind speed were in good agreement with the observations at nearly 


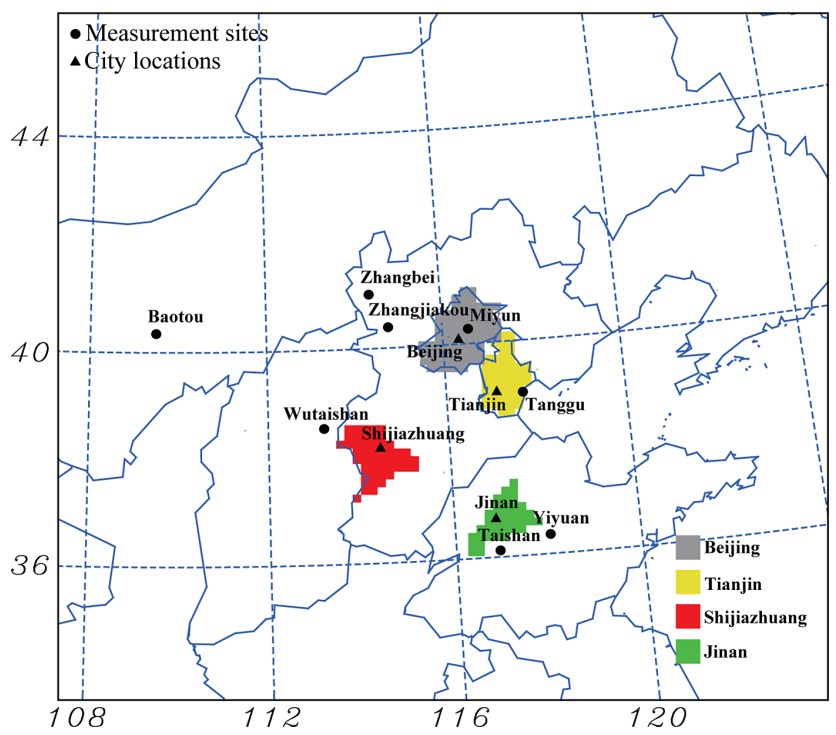

Figure 1. Geographic location of CRAES monitoring cities and CNMC measurement stations in the model domain. The gray, yellow, red, and green areas represent the districts of Beijing, Tianjin, Shijiazhuang, and Jinan, respectively.

all stations. A persistent underestimation of wind speed by the models was found at the Wutaishan and Taishan sites. The modeled wind speed presented in Fig. 4 was obtained by converting the output values of the first layer ( 90 to $200 \mathrm{~m}$ ) to near-surface wind $(\sim 10 \mathrm{~m})$ according to Monin-Obukhov similarity theory (Ding et al., 2001). These two sites are located on a mountainside at elevations of 2208 and $1533 \mathrm{~m}$, respectively. Thus, the underestimation may be attributed to the different elevations between the simulation and the observation. As shown in Fig. 5, the modeled wind directions did not coincide well with the observed data. A direct comparison is difficult to achieve because of the difference in time resolutions between the site measurements (10 min, average) and the model output $(1 \mathrm{~h})$. Nevertheless, the variation trends of the modeled and observed wind directions are similar at most sites, as shown in Fig. 5. The monthly modeled precipitation over the NCP is compared to the observations of surface monitoring data from 87 CNMC sites in Fig. 6. The modeling system generally performed well capturing the distribution patterns and seasonal variation features of precipitation in the megacities of Beijing and Tianjin as well as Inner Mongolia, Hebei, and Shandong provinces. However, the modeled results underestimated the precipitation in northern Beijing and the northern part of Hebei Province in July, which was perhaps the source of the error of wet deposition estimation. The relative humidity was also underestimated in the second half of February at the Miyun and Tanggu sites, and for almost the whole of July at Miyun as shown in Fig. 3. Underestimation most often happened when the relative humidity exceeded $70 \%$, implying that the model did not accurately deal with high relative humidity over this region. The comparison of the modeled and observed precipitation and relative humidity in Beijing are discussed in detail below.
The modeled hourly $\mathrm{NO}_{2}, \mathrm{O}_{3}, \mathrm{PM}_{2.5}$, and visibility in February and July were also compared with the observed data provided by the Chinese Research Academy of Environmental Sciences (CRAES). This data set comprised the real-time mass burden of air pollutants in Beijing (Gao et al., 2012). The results are shown in Figs. 7 and 9. The statistical parameters - including means, standard deviations, and correlation coefficients between the observations and simulations - are listed in Table 2. These metrics were used to evaluate model performance, following the work of Yu et al. (2006). The model efficiently captured the daily variation of the pollutant gases and the high mass burden of $\mathrm{PM}_{2.5}$ in these 2 months as shown in Fig. 7. Table 2 shows that most of the correlation coefficients were higher than 0.6, and the means and standard deviations of the simulations were also similar to those of the observations. However, the correlation coefficients of $\mathrm{PM}_{2.5}$ and $\mathrm{NO}_{2}$ were lower than 0.5 in July. From Fig. 7 and the means and standard deviations in Table 2, we see that the model generally overestimated $\mathrm{PM}_{2.5}$ in the middle of July, and the fluctuation range of modeled $\mathrm{NO}_{2}$ was larger than that of the observation results. The comparison of modeled and observed daily precipitation in Beijing is given in Fig. 8 (the observation data was collected from CNMC). The modeled precipitation in July was clearly lower than that of observation in the middle of July. This may result in weaker wet deposition, which can cause an overestimation of the aerosol burden in Beijing. For the simulated $\mathrm{NO}_{2}$, the larger diurnal variation was perhaps caused by the uncertainties from the related gas-phase chemical scheme in CB05. The modeled visibility also agreed well with the observations, particularly for visibility lower than $10 \mathrm{~km}$, suggesting that the model could provide reasonable simulation during haze occurrence. The means and standard deviations of 
Table 2. Statistical summary of the comparisons of $\mathrm{PM}_{2.5}, \mathrm{O}_{3}, \mathrm{NO}_{2}$, and visibility between simulation and observations in Beijing.

\begin{tabular}{lllrrrrr}
\hline & & $N^{\mathrm{a}}$ & $C_{\text {mod }}^{\mathrm{b}}$ & $C_{\text {obs }}^{\mathrm{c}}$ & $\sigma_{\text {mod }}^{\mathrm{d}}$ & $\sigma_{\text {obs }}^{\mathrm{e}}$ & $R^{\mathrm{f}}$ \\
\hline \multirow{2}{*}{$\mathrm{PM}_{2.5}$} & Feb & 665 & 133.05 & 127.5 & 102.41 & 129.7 & 0.76 \\
& Jul & 663 & 112.78 & 89.92 & 74.09 & 72.98 & 0.43 \\
\hline \multirow{2}{*}{$\mathrm{O}_{3}$} & Feb & 621 & 15.74 & 16.10 & 14.04 & 14.04 & 0.78 \\
& Jul & 630 & 56.59 & 48.75 & 38.44 & 36.21 & 0.74 \\
\hline \multirow{2}{*}{$\mathrm{NO}_{2}$} & Feb & 672 & 33.94 & 44.18 & 17.59 & 24.98 & 0.75 \\
& Jul & 626 & 25.29 & 24.08 & 17.01 & 11.62 & 0.42 \\
\hline \multirow{2}{*}{ Visibility } & Feb & 672 & 10.97 & 10.78 & 6.53 & 7.27 & 0.76 \\
& Jul & 744 & 8.06 & 9.64 & 5.74 & 6.48 & 0.65 \\
\hline
\end{tabular}

${ }^{a}$ Number of samples, ${ }^{b}$ total mean of observations, ${ }^{c}$ total mean of simulations, ${ }^{d}$ standard deviation of observations, ${ }^{\mathrm{e}}$ standard deviation of simulations, ${ }^{\mathrm{f}}$ correlation coefficient between observation and simulation.
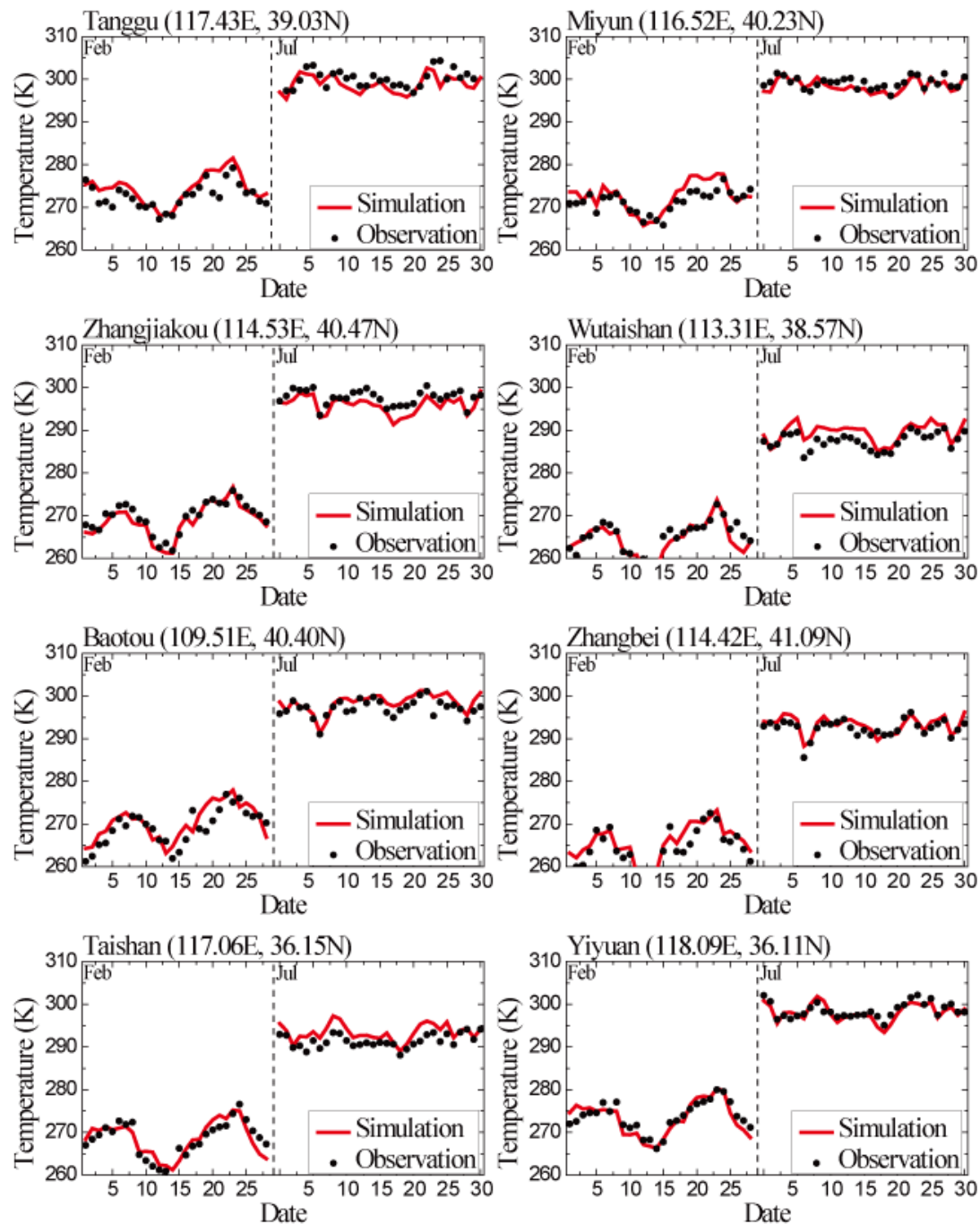

Figure 2. Observed (black circles) and modeled (solid red lines) daily-average temperatures (K) at eight stations in February and July 2011. 

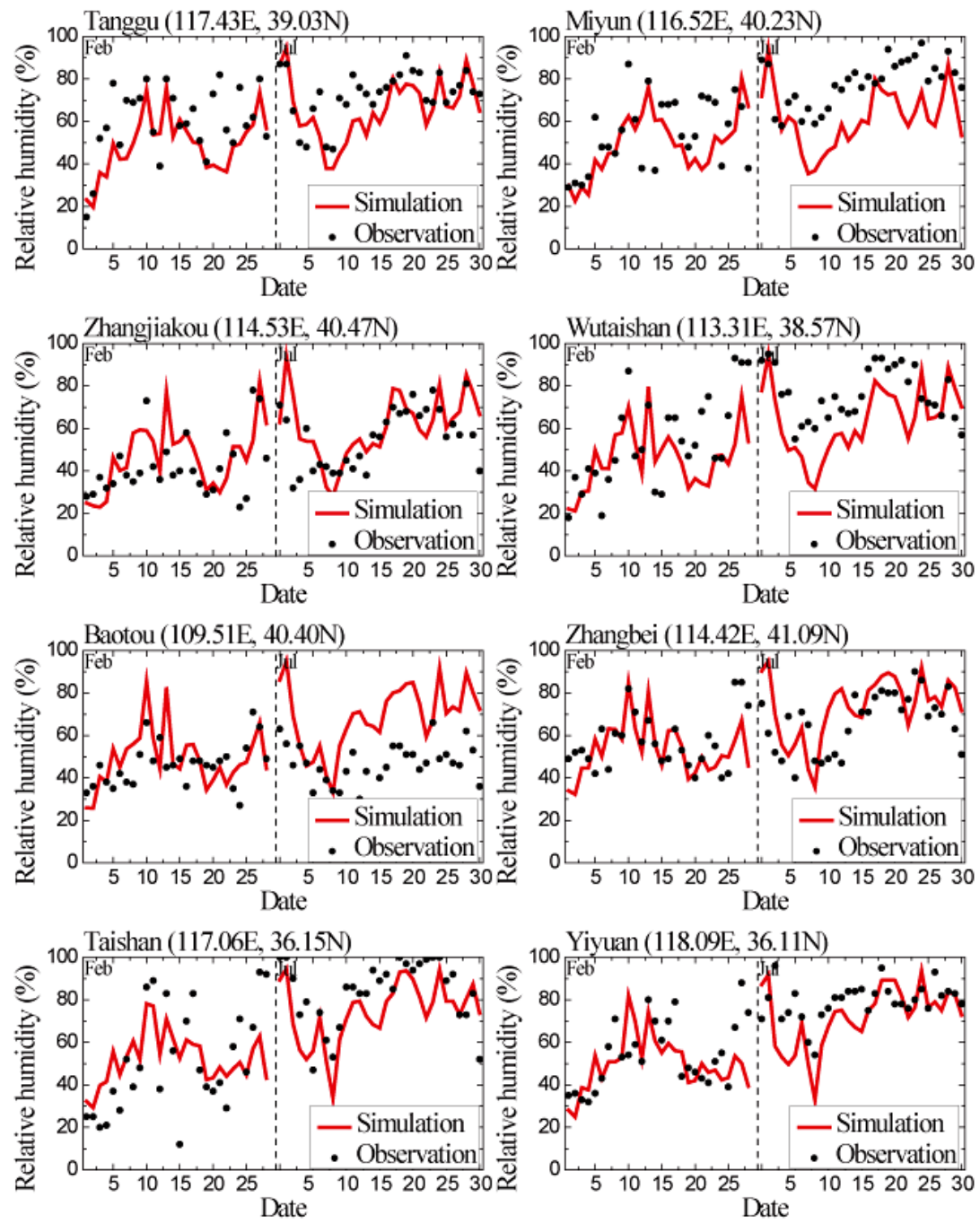

Figure 3. Same as Fig. 2 but for relative humidity (\%).

the modeled visibility were quite similar to those of observations. Meanwhile, continuous haze was found in the modeled and observed results in the middle of July, as shown in Fig. 9. This phenomenon indicates that, although the model overestimated the mass burden of $\mathrm{PM}_{2.5}$, the visibility simulation during this period remained reliable. We also collected the hourly observation data of relative humidity from CRAES to evaluate the model performance in Beijing, and the comparison is shown in Fig. 10. Even though the model underestimated the relative humidity at the Miyun and Tangshan sites, the simulation results closely followed the observations in Beijing. The model only just overestimated the relative humidity when its value was lower than about $30 \%$. This evaluation indicates that the model more reliably simulates relative humidity in Beijing than in Miyun or Tangshan.

The modeled daily-average mass concentrations of the major aerosol components were compared with the observed data from the CRAES measurements, as shown in Fig. 11.
The observed data lacked information for the first half of February and a number of days in July because of instrument failure. Although the magnitudes of the mass concentrations between the simulation and the observation did not exactly coincide, the modeled results broadly reproduced the peaks of the observed data from 20 to 23 February and from 20 to $23 \mathrm{July}$; the modeled results also followed the seasonal variation features. For instance, the modeled and observed carbonaceous aerosols were both high in February and low in July. The model demonstrated an obvious systematic underestimation of organic carbon in these 2 months, as shown in Fig. 11. Numerous studies have reported that such a phenomenon is a common issue in regional chemistry and transport models (Heald et al., 2005; Koch et al., 2007). The simulation error was primarily due to the uncertainties in the estimation of VOCs and primary organic aerosol emissions and the formation mechanism of secondary organic aerosol (Kroll et al., 2006; Henze and Seinfeld, 2006; Yu et al., 

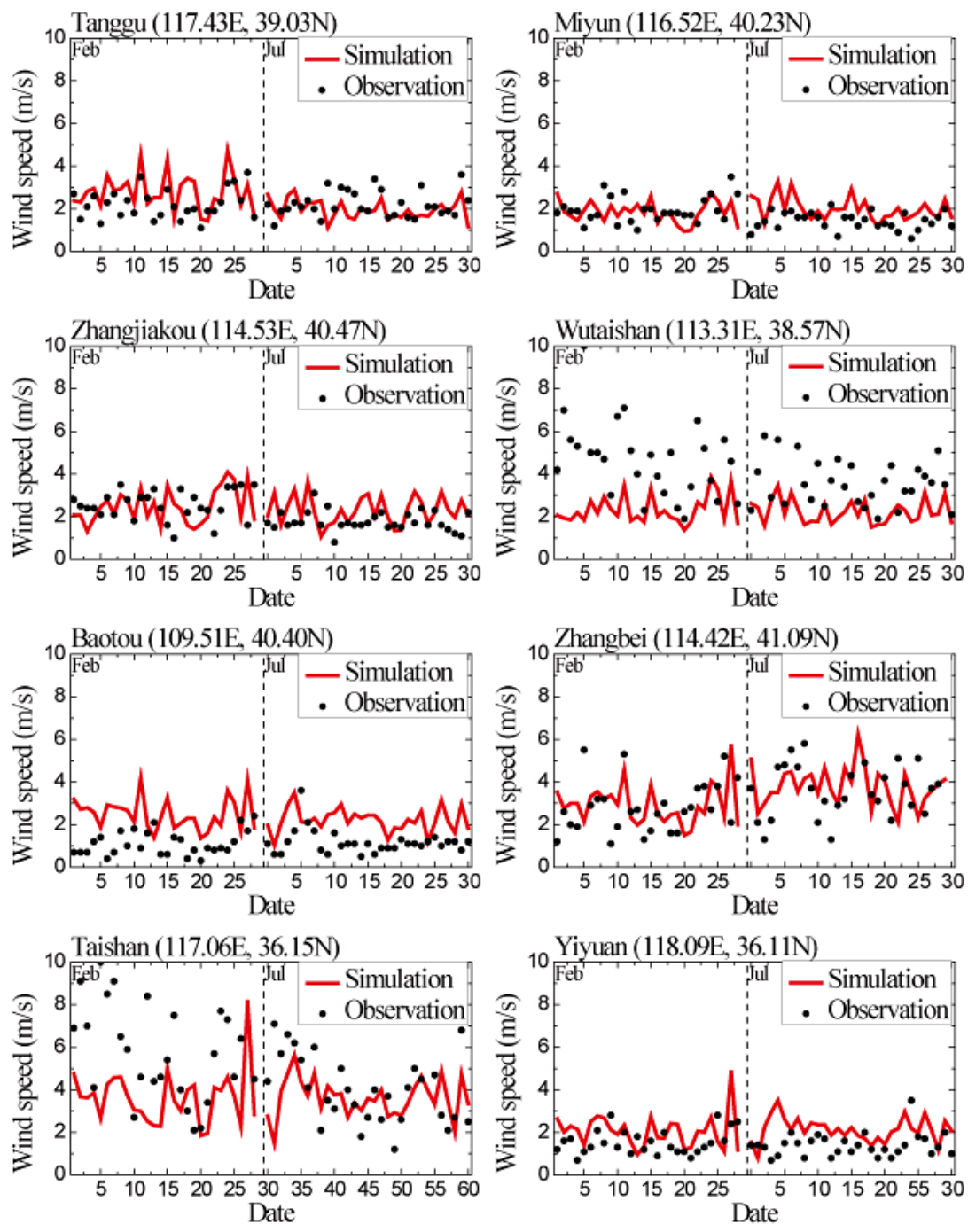

Figure 4. Same as Fig. 2 but for wind speed $\left(\mathrm{m} \mathrm{s}^{-1}\right)$.

2007). However, this discrepancy did not significantly affect the accuracy of the visibility simulation. Therefore, these evaluations suggest that the modeling system can reasonably simulate the meteorological field, the mass burdens of major aerosol components, and the surface visibility in February and July 2011.

\section{Results and discussions}

\subsection{Distribution features of aerosol concentration and visibility}

As shown in Figs. 7 to 11, two typical heavy air pollution episodes occurred over the NCP from 20 to 23 February and from 20 to 23 July. These two periods were selected to investigate the distribution features of pollutants and visibility over the NCP during occurrences of heavy pollution in different seasons. Figure 12 presents the horizontal distributions of the daily-average mass concentration of $\mathrm{PM}_{2.5}$ and surface wind field over the NCP from 20 to 23 February and from 20 to 23 July. The heavy mass burden of $\mathrm{PM}_{2.5}$ (over $120 \mu \mathrm{g} \mathrm{m}^{-3}$ ) was mainly concentrated in the megacities of Beijing and Tianjin, the whole area of Hebei Province and northwest part of Shandong Province. The mass concentration of $\mathrm{PM}_{2.5}$ in February - which exceeded $200 \mu \mathrm{g} \mathrm{m}^{-3}$ in Beijing, Tianjin, Shijiazhuang, and Jinan - was higher than that in July. The high mass burden of $\mathrm{PM}_{2.5}$ appeared in the same regions as those in February, broadly ranging from 75 to $200 \mu \mathrm{g} \mathrm{m}^{-3}$ in July, and rarely exceeded $200 \mu \mathrm{g} \mathrm{m}^{-3}$ over the entire NCP. The high mass burden of $\mathrm{PM}_{2.5}$ in Beijing generally appeared when the NCP was dominated by the south wind field, which transported air masses from the polluted regions in the south. The heavy $\mathrm{PM}_{2.5}$ mass burden may have been transported to northeastern China and the Bohai Sea by the strong south wind from 22 to 23 February and 

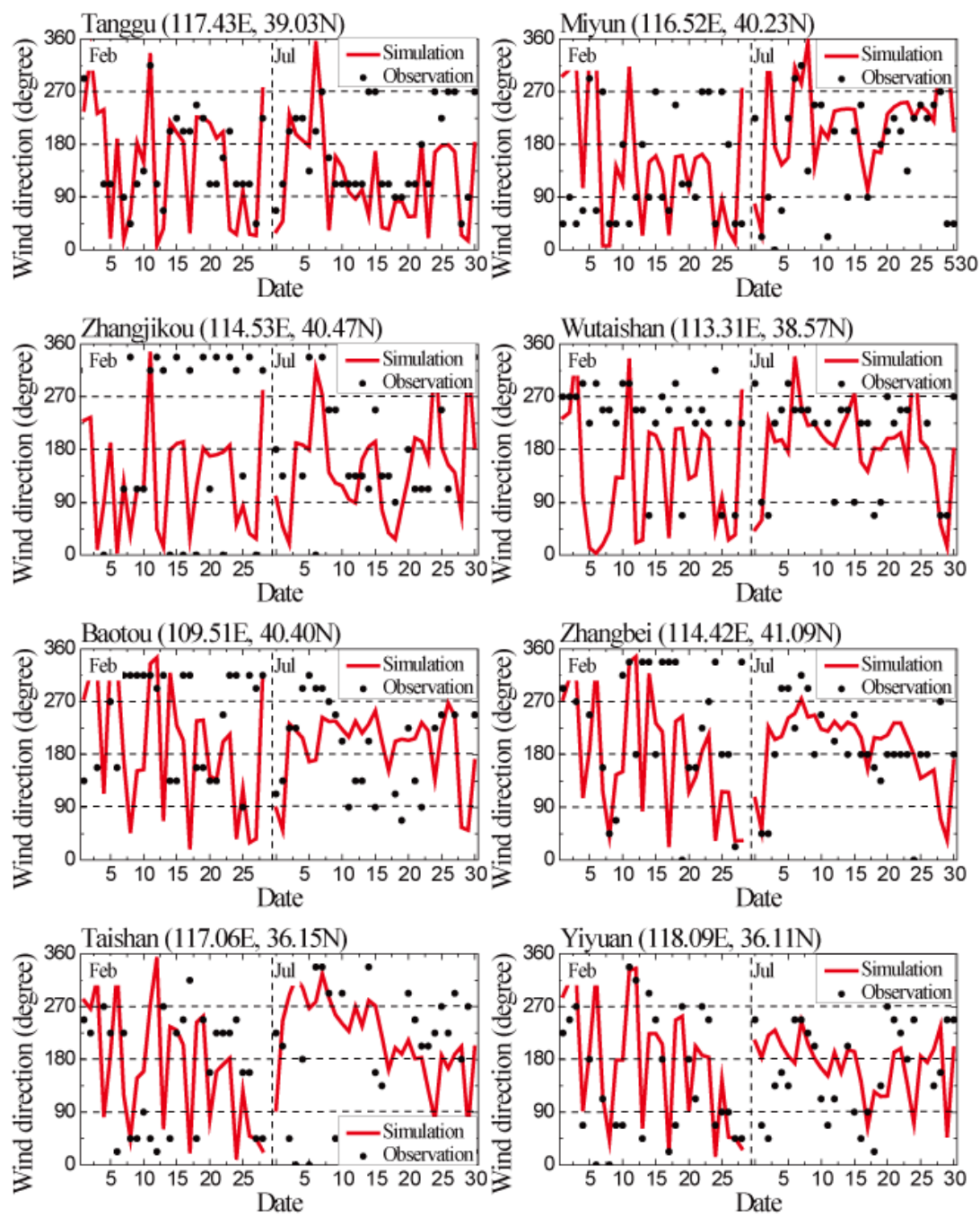

Figure 5. Same as Fig. 2 but for wind direction $\left({ }^{\circ}\right)$.

on 23 July, respectively, thereby increasing the mass concentration of $\mathrm{PM}_{2.5}$ by 45 to $125 \mu \mathrm{g} \mathrm{m}^{-3}$ in these two regions, as shown in Fig. 12.

Figure 12 also presents the horizontal distributions of daily-average visibility and surface relative humidity over the NCP. The data show that haze cloud spreads throughout the NCP during each pollution episode. The visibility in most parts of Hebei and Shandong was generally less than $8 \mathrm{~km}$, decreasing to 3 to $5 \mathrm{~km}$ in the four urban areas in February and July. The distribution patterns of visibility broadly followed those of the $\mathrm{PM}_{2.5}$ mass burden, and the deterioration in visibility mainly appeared in the regions where the heavy $\mathrm{PM}_{2.5}$ mass burden was concentrated. The visibility generally decreased to 3 to $5 \mathrm{~km}$ when the mass concentration of $\mathrm{PM}_{2.5}$ exceeded $200 \mu \mathrm{g} \mathrm{m}^{-3}$ in February. However, similar values of visibility also appeared in July when the mass concentration of $\mathrm{PM}_{2.5}$ was in the range 120 to $200 \mu \mathrm{g} \mathrm{m}^{-3}$. Such a phenomenon was apparent on 23 July when the visibility over the entire Bohai Sea ranged from 3 to $5 \mathrm{~km}$ and the mass concentration of $\mathrm{PM}_{2.5}$ was maintained between 120 and $200 \mu \mathrm{g} \mathrm{m}^{-3}$. These differences may be due to the strong extinction of soluble particles caused by the high relative humidity (exceeding $70 \%$ ) in July, as shown in Fig. 12. This feature is discussed in detail below.

\subsection{Meteorological factors, major aerosol components, and their contributions to extinction in Beijing}

Figure 13a to $h$ present the time series of regional-average surface wind speed, relative humidity, and visibility, as well as the mass concentrations of $\mathrm{PM}_{2.5}$, sulfate, nitrate, ammonium, BC, and OC in Beijing in February and July 2011. The averages of these variables during the haze days in February and July are shown in Table 3. The mass burden of $\mathrm{PM}_{2.5}$ was the most important factor influencing changes of visibility, as it is generally inversely correlated with the variation of visibility. The mass concentrations of the three kinds of 

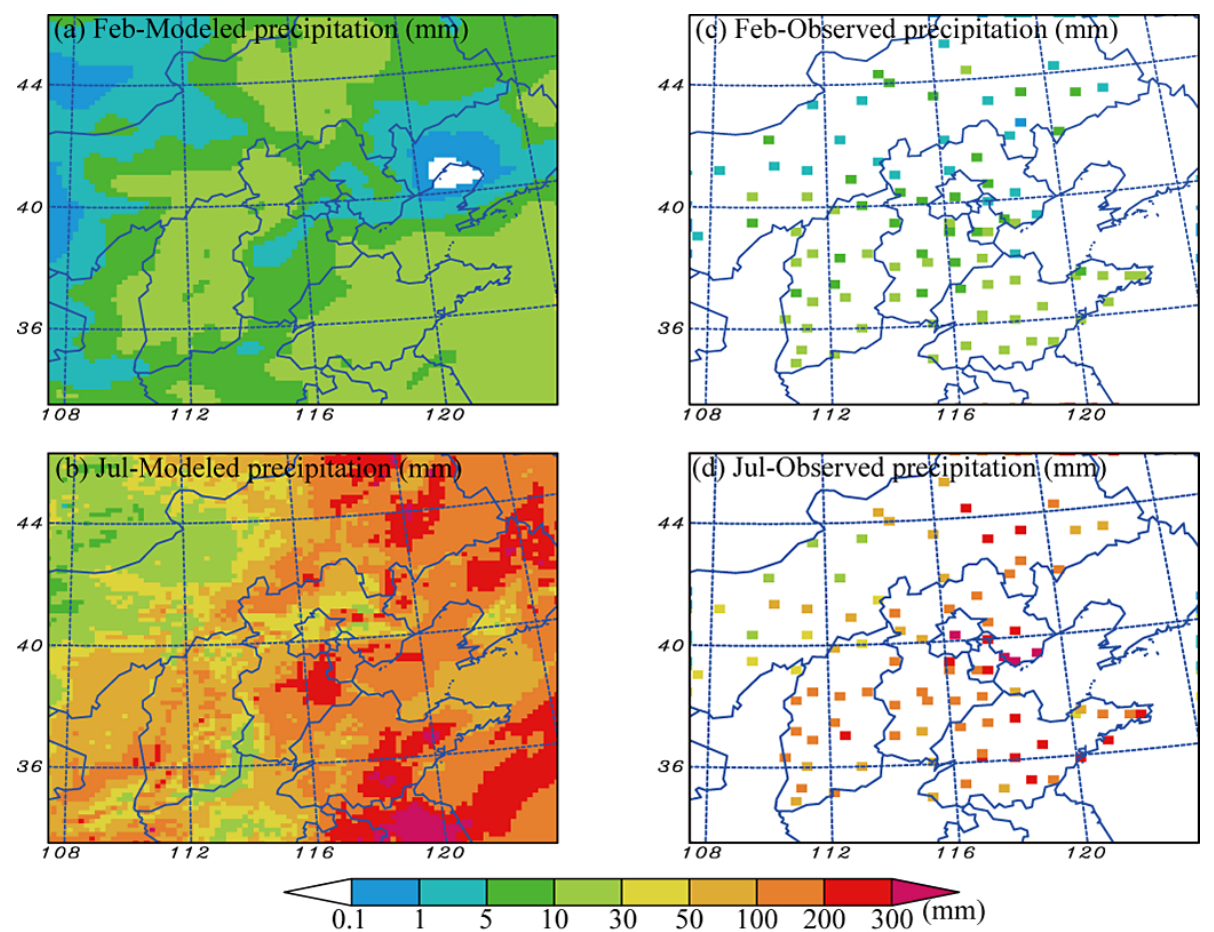

Figure 6. The horizontal distributions of the monthly precipitation ( $\mathrm{mm}$ ) from simulation and surface observation data in February and July 2011 over the NCP.
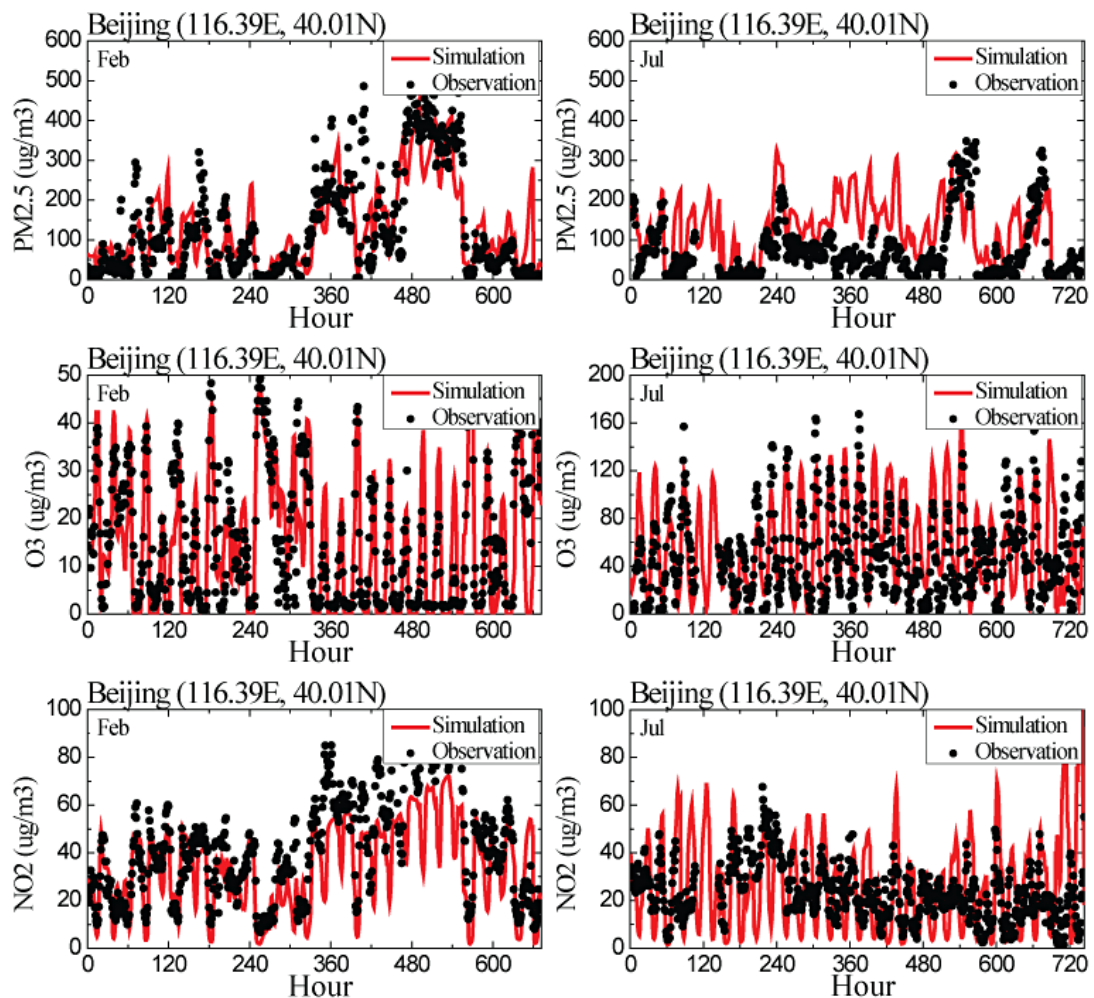

Figure 7. Observed (black circles) and modeled (red solid lines) hourly mass concentrations $\left(\mu \mathrm{g} \mathrm{m}^{-3}\right.$ ) of $\mathrm{PM}_{2.5}, \mathrm{O}_{3}$, and $\mathrm{NO}_{2}$ in February and July 2011 at Beijing. 

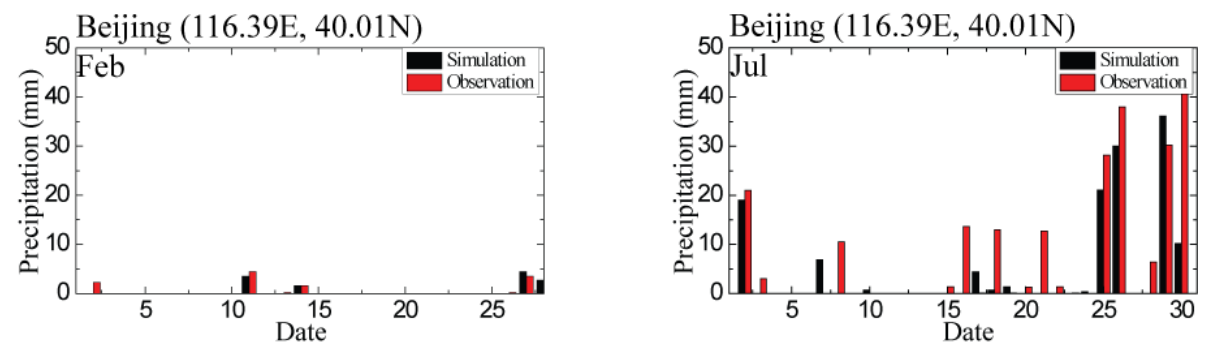

Figure 8. Observed and modeled daily precipitation (mm) in February and July 2011 in Beijing
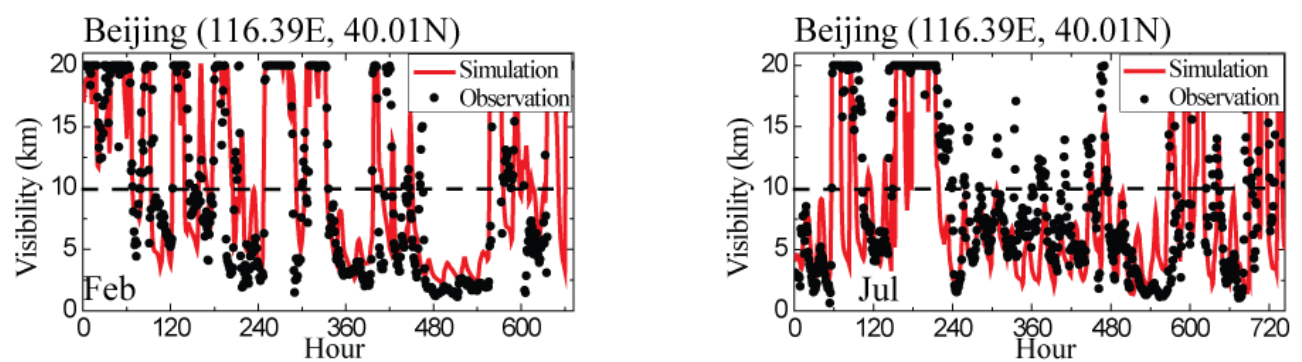

Figure 9. Observed (black circles) and modeled (solid red lines) hourly visibility (km) in February and July 2011 in Beijing.

inorganic salt - namely, nitrate, sulfate, and ammonium suggest that they were the three major aerosol components of $\mathrm{PM}_{2.5}$ in Beijing, as shown in Fig. 13e to f. The mass burden of organic carbon was comparable with that of nitrate, so the total mass burden of organic matter should be larger than that of nitrate. If not, then nitrate should be the main particulate pollutant during winter because the mass burden of nitrate was higher than those of the other components in February. Although the diurnal variation of nitrate concentration was significant in July, the daily maximum nitrate concentration was still larger than that of sulfate during the nighttime. These findings suggest that the emission from the transportation sector was the major source of secondary particles in Beijing. The mass burden of carbonaceous aerosols was high in February and low in July. In addition to the diffusion conditions, the strong emissions of coal and biomass burning were the main reasons for the high values of carbonaceous aerosols during the winter (Zhang et al., 2014).

As shown in Table 3, July had a greater number of haze days than February, and the average visibility during haze days in July was lower than that in February. These features indicate that air pollution was more serious in July than in February. However, the average mass concentration of $\mathrm{PM}_{2.5}$ in July during haze days was obviously lower than that in February. In addition, Table 3 shows that the relatively low value of $\mathrm{PM}_{2.5}$ mass concentration in July was primarily due to the small quantities of carbonaceous aerosol burden. Meanwhile, the total mass burden of nitrate, sulfate, and ammonium was higher in July than in February. Therefore, deterioration in visibility was caused by the simultaneous occurrence of the high mass burden of soluble particles and high
Table 3. The number of haze days in February and July in Beijing. Also shown are the regional- and temporal-average surface wind speed $\left(\mathrm{m} \mathrm{s}^{-1}\right)$, visibility $(\mathrm{km})$, relative humidity $(\%)$, and mass concentrations $\left(\mu \mathrm{g} \mathrm{m}^{-3}\right)$ of sulfate, nitrate, ammonium, BC, OC, and $\mathrm{PM}_{2.5}$ during the haze days in February and July in Beijing.

\begin{tabular}{lrr}
\hline variables & February & July \\
\hline Number of haze days & 7 & 13 \\
Wind speed & 3.13 & 3.41 \\
Visibility & 6.22 & 5.73 \\
Relative humidity & 55.80 & 74.32 \\
\hline Mass concentration & & \\
\hline Sulfate & 37.99 & 52.32 \\
Nitrate & 54.78 & 48.37 \\
Ammonium & 30.15 & 33.60 \\
BC & 13.29 & 4.31 \\
OC & 19.51 & 5.16 \\
PM 2.5 & 174.26 & 148.32 \\
\hline
\end{tabular}

relative humidity in July. The difference in the haze formation mechanism during winter and summer was associated with the different $\mathrm{PM}_{2.5}$ particle composition and the ambient relative humidity.

Figure $13 \mathrm{~g}$ to $\mathrm{h}$ present the time series of the regionalaverage contribution ratios of sulfate, nitrate, ammonium, $\mathrm{BC}, \mathrm{OC}$, and other components (dust, sea salt, and unspecified anthropogenic mass) to the total surface extinction in Beijing in February and July. The monthly means of these contribution ratios are shown in Table 4. The contribution ratios were calculated by subtracting the extinction coefficient 

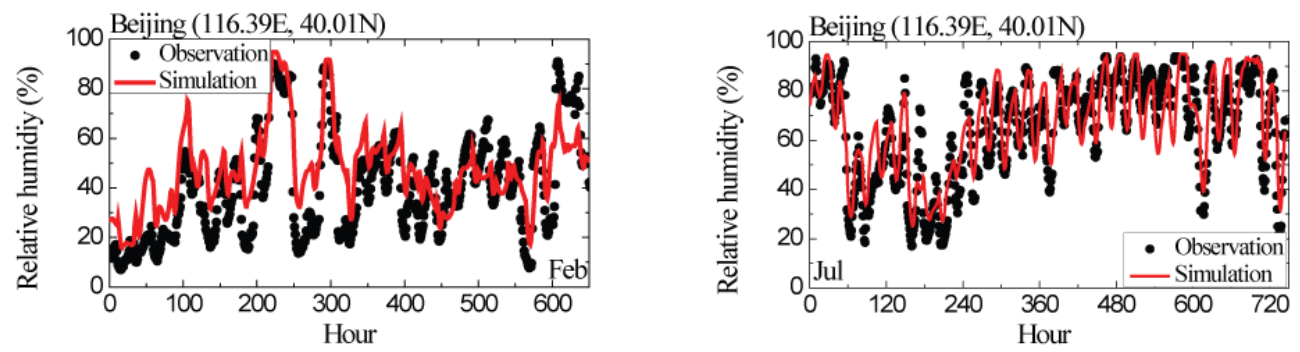

Figure 10. Observed (black circles) and modeled (solid red lines) hourly relative humidity (\%) in February and July 2011 in Beijing.

with and without each aerosol component when estimating the aerosol optical properties by using the scheme introduced in Sect. 2. The inorganic salts nitrate, sulfate, and ammonium significantly contributed to the surface extinction in Beijing, which was $\sim 70 \%$ in February and over $80 \%$ in July. Carbonaceous aerosol had a 20 and $5 \%$ contribution in February and July, respectively, whereas other aerosol components had around a $10 \%$ contribution. These ratios generally followed the magnitude of the mass concentrations. Except for the diurnal variation of nitrate in July, the contribution ratios of each aerosol component did not significantly change when the mass concentration of $\mathrm{PM}_{2.5}$ exceeded $\sim 50 \mu \mathrm{g} \mathrm{m}^{-3}$. In contrast, when the mass concentration of $\mathrm{PM}_{2.5}$ decreased to less than $50 \mu \mathrm{g} \mathrm{m}^{-3}$, the contribution ratios of carbonaceous aerosol and other components obviously increased. A higher mass concentration of $\mathrm{PM}_{2.5}$ corresponded to a higher contribution ratio of the three inorganic salts. This feature confirmed that nitrate, sulfate, and ammonium were the major aerosol components influencing haze formation in Beijing.

\subsection{Haze occurrence threshold in Beijing}

It can be seen from Fig. 13 that the mass concentration of $\mathrm{PM}_{2.5}$ was closely inversely correlated with visibility. However, when the mass concentration of $\mathrm{PM}_{2.5}$ was located in different mass value intervals, the influence on the visibility was not consistent. Figure 14a shows the time series of the regional mean mass concentration of $\mathrm{PM}_{2.5}$ and visibility in Beijing from 23 to 25 July. The air quality for these 3 days improved over time, and the visibility continuously increased. The mass concentration of $\mathrm{PM}_{2.5}$ decreased from $260 \mu \mathrm{g} \mathrm{m}^{-3}$ on 23 July to $20 \mu \mathrm{g} \mathrm{m}^{-3}$ on 25 July. For the convenience, the time taken for the decrease was divided into periods $\mathrm{A}, \mathrm{B}$, and $\mathrm{C}$, as shown in the figure. In period $\mathrm{A}$, the mass concentration of $\mathrm{PM}_{2.5}$ changed from 260 to $120 \mu \mathrm{g} \mathrm{m}^{-3}$, decreasing by about $140 \mu \mathrm{g} \mathrm{m}^{-3}$, while the visibility increased by less than $5 \mathrm{~km}$; in period $\mathrm{B}$, the mass concentration of $\mathrm{PM}_{2.5}$ changed from 120 to $50 \mathrm{\mu g} \mathrm{m}^{-3}$, decreasing by about $70 \mu \mathrm{g} \mathrm{m}^{-3}$, and the visibility increased obviously, from 5 to about $20 \mathrm{~km}$; and finally, in period C, the mass concentration of $\mathrm{PM}_{2.5}$ changed from 35 to $20 \mu \mathrm{g} \mathrm{m}^{-3}$, decreasing by only $15 \mu \mathrm{g} \mathrm{m}^{-3}$, and the visibility increased dramatically by $60 \mathrm{~km}$. The above analysis indicated that,
Table 4. Regional- and monthly-average extinction contribution ratios (\%) of sulfate, nitrate, ammonium, BC, OC, and other aerosols (dust, sea salt, and unspecified anthropogenic mass) in February and July in Beijing.

\begin{tabular}{lrrrrrr}
\hline & Sulfate & Nitrate & Ammonium & BC & OC & Others \\
\hline Feb & 22.73 & 29.69 & 17.13 & 5.05 & 13.22 & 12.18 \\
Jul & 39.31 & 24.77 & 21.88 & 0.33 & 3.96 & 9.74 \\
\hline
\end{tabular}

even though emission reduction measures were taken to dramatically decrease the $\mathrm{PM}_{2.5}$ mass burden, the improvement of visibility would still be weak if the mass concentration of $\mathrm{PM}_{2.5}$ remained at a high level. Only when the mass concentration of $\mathrm{PM}_{2.5}$ decreased to the certain value range did the visibility improve. The visibility was calculated by using Eq. (2) in the modeling system. The aerosol extinction coefficient should be the key factor influencing the visibility. From Fig. 14b, the variation of the extinction coefficient and mass concentration of $\mathrm{PM}_{2.5}$ were quite similar. We therefore deduced that, when the value of extinction coefficient became small, the value of visibility could change dramatically with only a micro-variation of the extinction coefficient. This should be the main factor causing the drastic change of visibility during period $\mathrm{C}$. Therefore, strictly speaking it was necessary to distinguish the atmospheric haze and the atmospheric pollution. That is, an improvement of air quality with decreasing mass concentrations of pollutants did not mean that the haze disappeared. If the occurrence of haze was controlled by decreasing mass concentration of $\mathrm{PM}_{2.5}$ in the atmosphere, a reasonable solution was to set a haze occurrence threshold interval, corresponding to the values of mass concentration of $\mathrm{PM}_{2.5}$ when the visibility reached $10 \mathrm{~km}$ under different ambient conditions. Only by strictly keeping the mass concentration of $\mathrm{PM}_{2.5}$ below this threshold did the visibility improve. Otherwise, even with the emission reduction measures taken when a heavy pollution event appears, the improvement of visibility would be very small if the mass concentration of $\mathrm{PM}_{2.5}$ failed to fall below the values of the haze occurrence threshold. Furthermore, the specific value of the threshold is closely related to the pollutant characteristics, meteorological conditions, and other factors. 

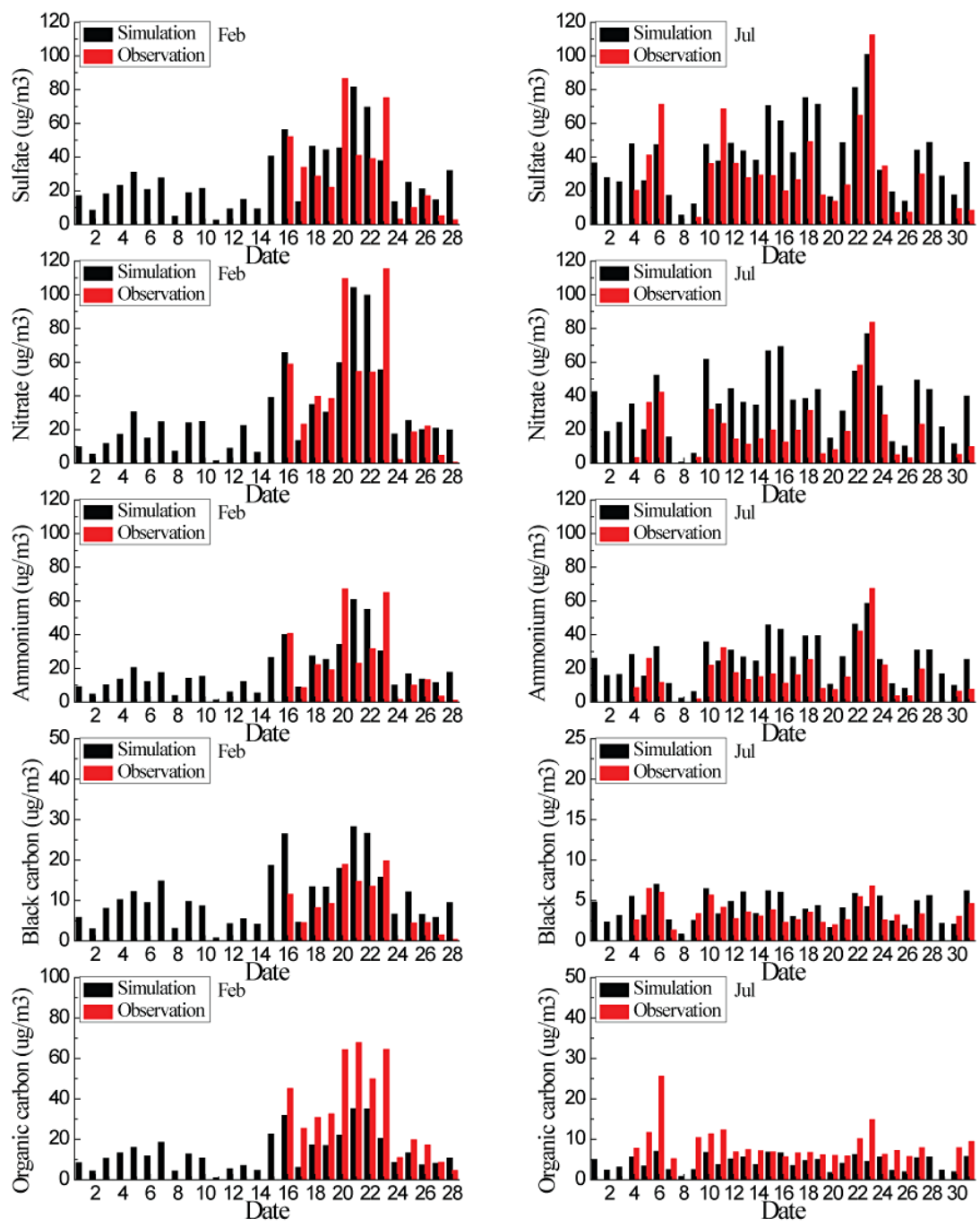

Figure 11. Observed (red bars) and modeled (black bars) daily-average mass concentrations $\left(\mu \mathrm{g} \mathrm{m}^{-3}\right.$ ) of sulfate, nitrate, ammonium, black carbon, and organic carbon in February and July 2011 in Beijing.

A sensitivity test was conducted to evaluate the mass concentration threshold of $\mathrm{PM}_{2.5}$ above which haze occurred in Beijing. First, the mass ratio of each aerosol component to the total mass burden of all aerosol particles was calculated from the results of the model simulation at every grid point. Then, the sensitivity test was conducted by using several possible values of the total aerosol burden and following the same ratio of each aerosol component at the same grid points to identify the mass concentration threshold of $\mathrm{PM}_{2.5}$ when the visibility decreased to $10 \mathrm{~km}$ under different relative humidity. The values of relative humidity were $70,75,80,85,88,89$, and $90 \%$. Lower values of relative humidity were disregarded because the water uptake of soluble particles was insignificant when the relative humidity was less than $70 \%$. Values of relative humidity higher than $90 \%$ indicate that light fog occurred as expressed by Wu et al. (2007). Figure $15 \mathrm{a}$ and $\mathrm{b}$ present the time series of the regional-average threshold of haze occurrence under different values of relative humidity from the sensitivity test in February and July in Beijing. The threshold changed significantly with the variation in relative humidity, and its declining trend increased with increasing relative humidity. The range of the mass concentration threshold reached $30 \mu \mathrm{g} \mathrm{m}^{-3}$ when the relative humidity changed from 70 to $90 \%$. Conversely, the threshold generally maintained a small change $\left(<5 \mu \mathrm{g} \mathrm{m}^{-3}\right)$ when the relative humidity was fixed. This indicates that, if the aerosol components did not have a dramatic variation in Beijing, a relatively fixed haze occurrence threshold could be determined.

However, the mass concentration threshold on 29 July increased by approximately $10 \mu \mathrm{g} \mathrm{m}^{-3}$ under the same relative humidity, as shown in Fig. 15b. Further analysis showed that this phenomenon might be related to the variation of aerosol in accumulation mode. Figure $15 \mathrm{c}$ to $\mathrm{h}$ present the time series 

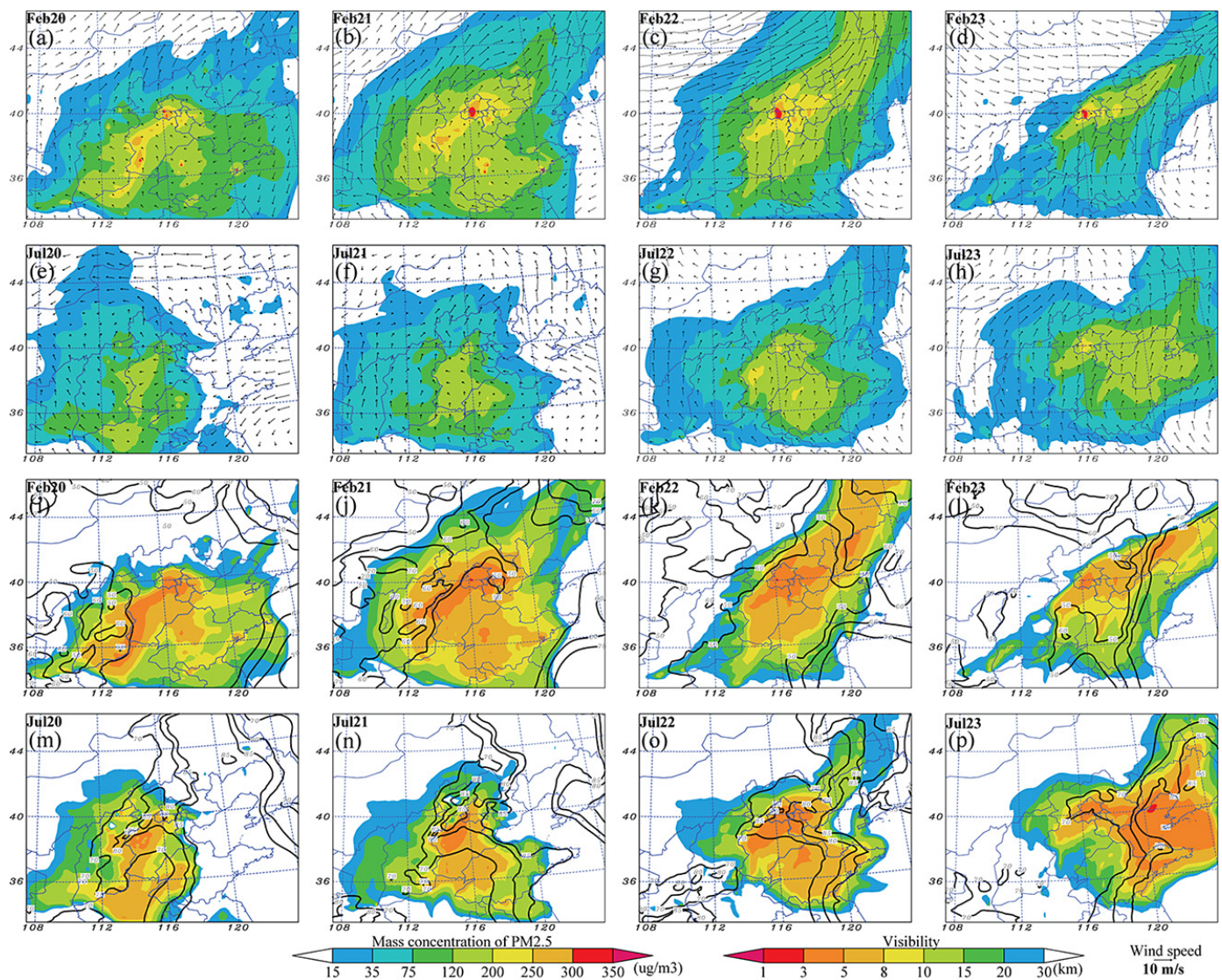

Figure 12. The horizontal distributions of the daily-average mass concentration of $\mathrm{PM}_{2.5}\left(\mu \mathrm{g} \mathrm{m}^{-3}\right.$; $\left.\mathbf{a}-\mathbf{h}\right)$ and visibility (km; $\left.\mathbf{i}-\mathbf{p}\right)$ from 20 to 23 February and 20 to 23 July over the NCP. Also shown are the wind field (arrows) and the relative humidity (\%; black contour lines).

of the regional-average mass ratios and contribution ratios of the three particle modes to the total aerosol burden and the total extinction, respectively. As seen in Fig. 15e and h, the extinction contribution of accumulation-mode particles was above $97 \%$ due to the high mass concentration ratio and extinction efficiency. However, the extinction contribution of accumulation-mode particles on 29 July decreased by about $5 \%$. Therefore, we deduced there should be a high correlation between the haze occurrence threshold and extinction contribution of accumulation-mode particles. Furthermore, it can be seen from Fig. $15 \mathrm{j}$ that the visibility on 29 July rose rapidly from less than $5 \mathrm{~km}$ to more than $20 \mathrm{~km}$. Thus, it can be deduced that a weather process beneficial to pollutant scavenging eliminated the mass concentration of accumulation-mode particles efficiently; i.e., the new particles in the atmosphere were eliminated immediately before coagulation or condensation in this period. The mass concentration ratio and extinction contribution ratio of Aitkenmode particles increased by about 10 and $5 \%$, respectively. This is the major reason for the decreasing extinction contribution ratio of accumulation-mode particles. Similar weather processes also occurred on 2-3, 5-10, and 25 July. During these periods the mass concentration of accumulation-mode particles decreased significantly. However, different from the condition on 29 July, the mass concentration ratio and extinction contribution of Aitken-mode particles did not change, but the mass concentration ratio of coarse-mode particles increased dramatically. Although the mass concentration of the coarse-mode particles accounted for $10-20 \%$ of the total aerosol, its extinction contribution was below $1 \%$ in most periods. Therefore, except for some special cases (e.g., the dust event), the influence of coarse-mode particles on the extinction was weaker than other modes. This was also the main reason for the lack of significant variation of the extinction contribution ratio of accumulation-mode particles in these three processes.

Generally speaking, besides relative humidity, the haze occurrence threshold is also sensitive to the extinction contribution ratio of accumulation-mode particles. From the above analysis, the mass concentration ratio of accumulation-mode particles generally remained at a high level and the fluctuation range was small during the heavy-pollution episode in Beijing. The variation range of haze occurrence threshold was less than $5 \mu \mathrm{g} \mathrm{m}^{-3}$ when the relative humidity was fixed. The increase of the haze occurrence threshold due to the variation of the extinction contribution of accumulation-mode 


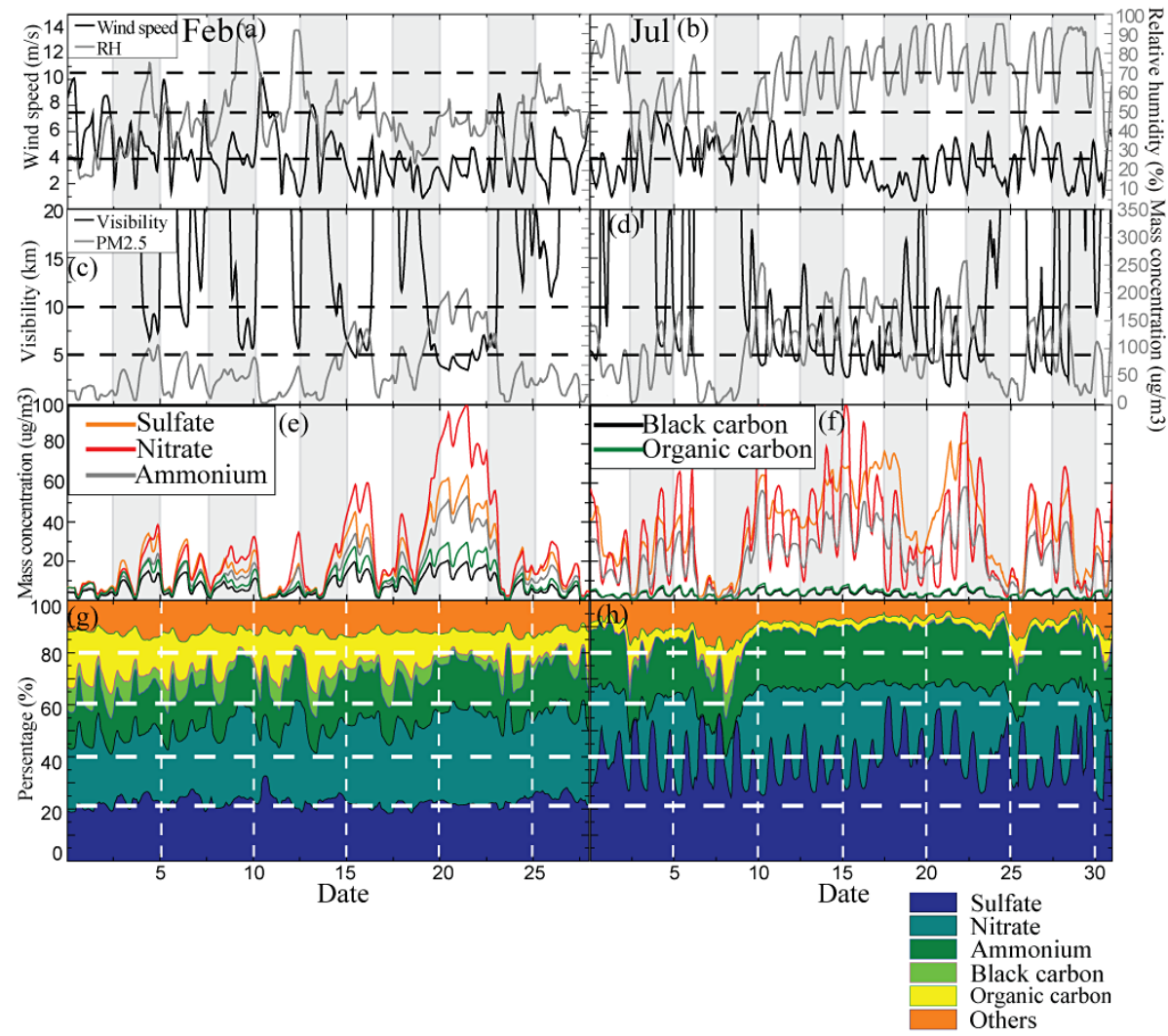

Figure 13. Time series of the regional-average surface wind speed $\left(\mathrm{m} \mathrm{s}^{-1}\right)$, relative humidity (\%), visibility (km), and $\mathrm{PM}_{2.5} \mathrm{mass}$ concentrations $\left(\mu \mathrm{g} \mathrm{m}^{-3}\right)$ in February and July in Beijing (a-d). Also shown are the mass concentrations $\left(\mu \mathrm{g} \mathrm{m}^{-3}\right.$; e-f) and extinction contribution ratios ( $\mathbf{g}-\mathbf{h})$ of sulfate, nitrate, ammonium, BC, OC, and other aerosols (dust, sea salt, and unspecified anthropogenic mass).

Table 5. Regional- and monthly-average mass concentration threshold of $\mathrm{PM}_{2.5}\left(\mu \mathrm{g} \mathrm{m}^{-3}\right)$ under different relative humidities from the sensitivity test in Beijing.

\begin{tabular}{lrrrrrrr}
\hline & $70 \%$ & $75 \%$ & $80 \%$ & $85 \%$ & $88 \%$ & $89 \%$ & $90 \%$ \\
\hline Feb & 82.08 & 78.01 & 72.34 & 64.54 & 58.27 & 55.87 & 53.22 \\
Jul & 83.08 & 78.64 & 72.46 & 64.01 & 57.35 & 54.82 & 52.10 \\
\hline
\end{tabular}

particles only appeared when the mass burden of Aitkenmode particles increased in clean periods. The reason for this phenomenon is that the extinction efficiency of Aitken-mode particles is far smaller than that of accumulation-mode particles. Therefore, more Aitken-mode particles are needed to form the haze. However, smaller particles generally existed during the clean period as shown by the simulation results, which means the haze did not appear. Thus, the influence of the extinction contribution of accumulation-mode particles on haze occurrence threshold can be neglected in Beijing. The relative humidity should be the only impact factor which needs to be considered.

The monthly means of the threshold of haze occurrence are shown in Table 5. It can be seen from Table 5 that, when the relative humidity changed from 70 to $90 \%$, the threshold interval increased from 52 to $83 \mu \mathrm{g} \mathrm{m}^{-3}$. Within a certain relative humidity range, the average monthly thresholds were similar in February and July. Here, the relationship between the haze occurrence threshold and relative humidity was fitted using

$\mathrm{RH}=a+b \times \exp (c \times M)$

where RH represents relative humidity; $M$ represents the $\mathrm{PM}_{2.5}$ mass concentration threshold; and $a, b$, and $c$ represent fitting parameters, and their values are listed in Table 6 . The fitting curve is shown in Fig. 16. From Table 6 it can be seen that the values of $R^{2}$ were all higher than 0.9 , indicating that their relationship can be described well by Eq. (3). Therefore, the fitting curves given in Fig. 16 can be used to capture the haze occurrence threshold in Beijing. Below $90 \%$ relative humidity, when $\mathrm{PM}_{2.5}$ mass concentration increases beyond the corresponding values on the curve, the haze should appear. Furthermore, the analysis in this study also indicated that the haze occurrence can be efficiently controlled by strictly restricting the $\mathrm{PM}_{2.5}$ mass concentration near or below the fitting curve. Otherwise, even a very large 
Table 6. Parameters of the exponential fit for the regional- and monthly-average $\mathrm{PM}_{2.5}$ mass concentration thresholds of haze occurrence in Beijing.

\begin{tabular}{lrrrr}
\hline & $a$ & $b$ & $c$ & $R$ square \\
\hline Feb & 96.3276 & -0.4859 & 0.0486 & 0.9997 \\
Jul & 96.8810 & 0.7367 & 0.0483 & 0.9997 \\
\hline
\end{tabular}

decrease of the $\mathrm{PM}_{2.5}$ mass burden would not reduce the possibility of haze occurrence.

\section{Conclusions}

In this study, the air quality modeling system RAMS-CMAQ, coupled with an aerosol optical property scheme, was used to simulate the meteorological field, the mass concentration of aerosols, and the surface visibility over the NCP in 2011. The modeling system provided reliable simulation results. The distribution patterns and time series of related meteorological factors and aerosol characteristic in February and July 2011 were analyzed to elucidate the seasonal variation features of the haze formation mechanism in Beijing and its surrounding regions. In addition, a sensitivity test was conducted to investigate the $\mathrm{PM}_{2.5}$ mass concentration threshold of haze occurrence in Beijing under distinct conditions. The results are summarized as follows:

1. The simulation results showed that the high mass burden of $\mathrm{PM}_{2.5}$ over the NCP was mainly concentrated in Beijing and Tianjin megacities, the whole area of Hebei Province, and the northwest part of Shandong Province. The daily-average mass concentration of $\mathrm{PM}_{2.5}$ over these regions was generally over $120 \mu \mathrm{g} \mathrm{m}^{-3}$ during the pollution episodes in February and July. The worst air quality over the NCP was found in Beijing because of the heavy daily-average mass burden of $\mathrm{PM}_{2.5}$, which exceeded $300 \mu \mathrm{g} \mathrm{m}^{-3}$ in February. The south wind that carried pollutants from the southern regions was an important source of the heavy aerosol loading in Beijing. In addition to the horizontal diffusion, the vertical convection also played an important role in the pollutant scavenging in Beijing.

2. The distribution patterns of visibility generally followed those of the $\mathrm{PM}_{2.5}$ mass burden. The daily-average visibility below $10 \mathrm{~km}$ covered most regions of the NCP during the pollution episodes in February and July and was below $5 \mathrm{~km}$ over the urban areas. The daily-average relative humidity rarely exceeded $90 \%$, suggesting that the haze cloud could spread throughout the NCP when the pollution episode appeared in both winter and summer.
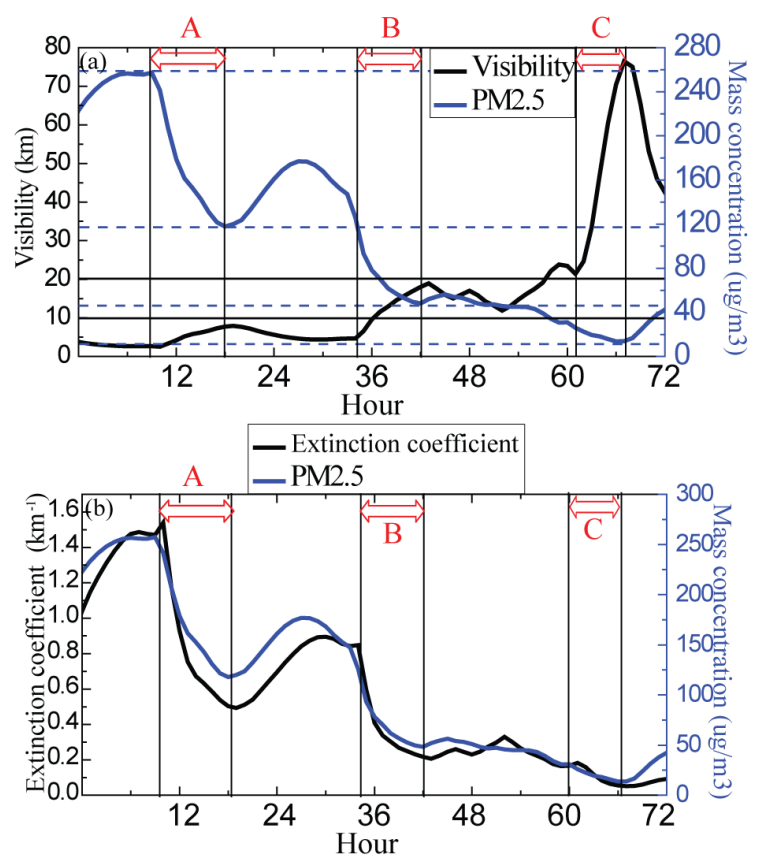

Figure 14. The time series of the regional-average visibility $(\mathrm{km})$ vs. mass concentration of $\mathrm{PM}_{2.5}$ (a) and extinction coefficient vs. mass concentration of $\mathrm{PM}_{2.5}$ (b) from July 23 to 25 in Beijing.

3. The simulation results showed that nitrate, sulfate, and ammonium were the three major aerosol components and the main causes of the visibility deterioration in Beijing. The mass burdens of these three inorganic salts were obviously higher than those of other aerosols, and their total contribution ratios to surface extinction reached $70 \%$ in February and $85 \%$ in July. Nitrate was also the first and second major contributor to surface extinction in February and July, respectively, implying that the emission from the transportation sector was the major source of secondary particles in Beijing. Carbonaceous aerosols accounted for $15 \%$ extinction in February and below $5 \%$ extinction in July. This indicates that the pollution status and emission sources were more complicated during winter in Beijing.

4. The haze formation mechanism in Beijing in winter was obviously different from that in summer. Firstly, the mass concentration of $\mathrm{PM}_{2.5}$ in winter was relatively higher and the components were complicated. The ratios of inorganic salts and carbonaceous aerosols were generally balanced. Therefore, the high mass concentration of $\mathrm{PM}_{2.5}$ and diverse aerosol components were the major reasons for the serious haze occurrence in winter. While the mass concentration of $\mathrm{PM}_{2.5}$ in summer was lower than that in winter, the ratio of hygroscopic inorganic salts - including sulfate, nitrate, and ammonium - increased, and their mass concentrations were even higher than those in winter. With higher relative 


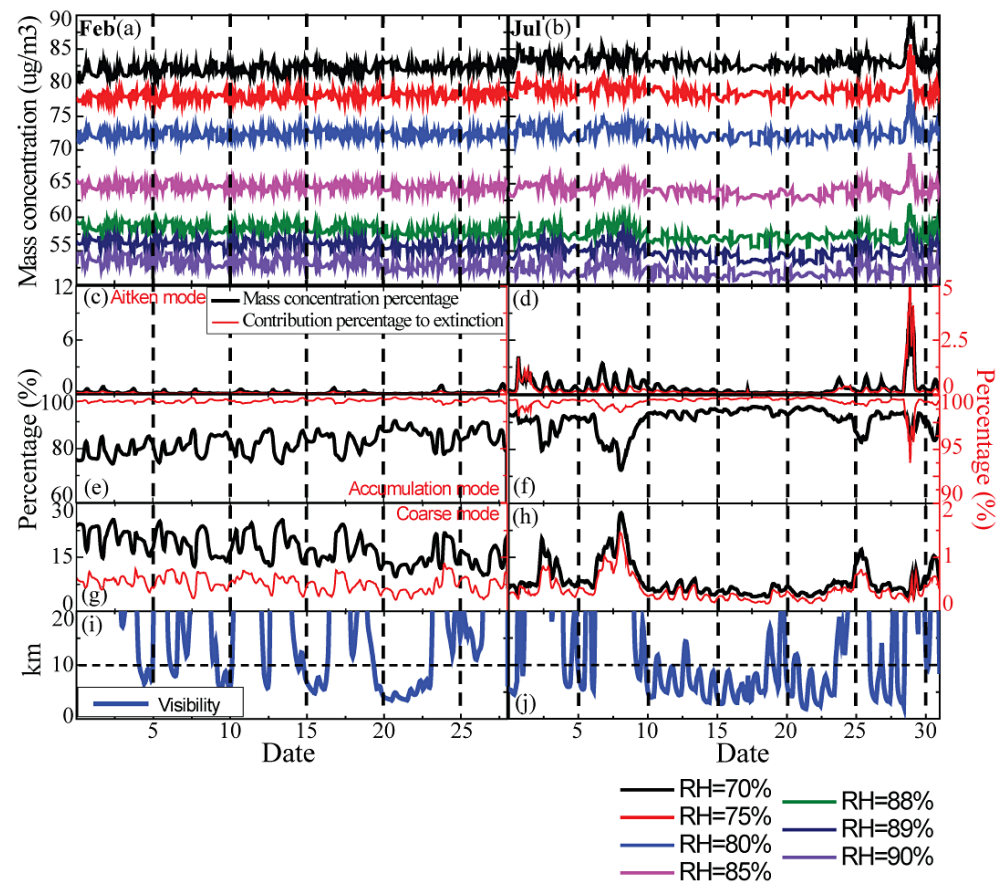

Figure 15. Time series of the regional-average mass concentration threshold of $\mathrm{PM}_{2.5}$ under different relative humidity (\%) from the sensitivity tests in February and July in Beijing. Also shown are the mass ratios and extinction contribution ratios (\%) of the Aitken, accumulation, and coarse modes, and visibility $(\mathrm{km})$.
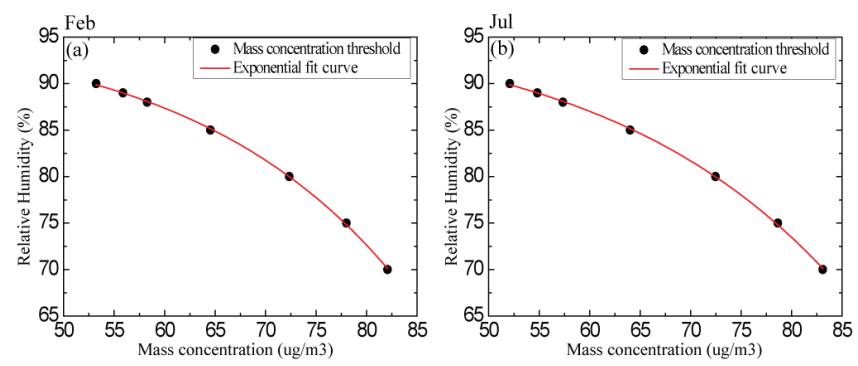

Figure 16. The relationship between regional- and monthly-average $\mathrm{PM}_{2.5}$ mass concentration threshold of haze occurrence and relative humidity in Beijing. Also shown are the exponential fitting curves.

humidity, serious haze may still form on an equal level to winter even though the mass concentration of $\mathrm{PM}_{2.5}$ is lower. The water uptake of hygroscopic components played a key role. This indicated that it is important to apply emission reduction measures based on the specific pollution and meteorological characteristics in different seasons. In this way, the possibility of haze occurrence can be effectively decreased.

5. From analysis, it was found that, even though the mass concentration of $\mathrm{PM}_{2.5}$ was closely inversely correlated with visibility, the influencing effect was diverse when the mass concentration of $\mathrm{PM}_{2.5}$ was located in different intervals. When the mass concentration of $\mathrm{PM}_{2.5}$ was larger than $100 \mu \mathrm{g} \mathrm{m}^{-3}$, the influence of its variation on visibility was very weak. Only when the mass concentration of $\mathrm{PM}_{2.5}$ was below a certain interval could its decrease make the visibility increase rapidly. Therefore, it was reasonable to set a haze occurrence threshold interval, and this was chosen to be the value of the mass concentration of $\mathrm{PM}_{2.5}$ when the visibility exceeded $10 \mathrm{~km}$ under different ambient conditions. If the mass concentration of $\mathrm{PM}_{2.5}$ failed to fall below the values of the haze occurrence threshold, the improvement of visibility would still be very weak when the emission reduction measures are taken.

6. Through the sensitivity experiment, this study estimated the haze occurrence threshold interval in Beijing and discussed related impact factors. Generally speaking, if the components of $\mathrm{PM}_{2.5}$ did not have a dramatic variation in Beijing, the haze occurrence threshold was only sensitive to the extinction contribution ratio of the accumulation-mode particles and relative humidity. Considering that the variation of the extinction contribution ratio of the accumulation-mode particles generally occurs in clean periods, the relative humidity should be the only impact factor. Finally, the relationship between the threshold of haze occurrence and relative humidity in winter and summer in Beijing was fitted by the exponential function, and these fitting curves could form a new theoretical basis for the further understanding and 
control of the haze formation in Beijing. As the analysis in this study, the fitting function could be applied to diagnose the haze events under ordinary conditions in Beijing. However, this function is not suitable for the haze over other regions, or in the event of uncommon pollution episodes (e.g., the dust storm) in Beijing, because the ratio of major aerosol components and particle size distribution would be different. Further research therefore remains necessary for other regions and various pollution features.

Acknowledgements. This study was supported by the National Basic Research Program of China (2014CB953802), the "Strategic Priority Research Program (B)" of the Chinese Academy of Sciences (XDB05030105, XDB05030102, XDB05030103), and the National Natural Science Foundation of China (41105106 and 41205123)

Edited by: V.-M. Kerminen

\section{References}

Benkovitz, C., Schultz, M., Pacyna, J., Tarrason, L., Dignon, J., Voldner, E., Spiro, P., Logan, J., and Graedel, T.: Global gridded inventories of anthropogenic emissions of sulfur and nitrogen, J. Geophys. Res., 101, 29239-29254, 1996.

Bhave, P. V., Roselle, S. J., Binkowski, F. S., Nolte, C. G., Yu, S. C., Gipson, G. L., and Schere, K. L.: CMAQ Aerosol Module Development: Recent Enhancements and Future Plans, Paper presented at 3rd Annual CMAS Models-3 Users' Conference, Commun. Model., and Anal. Syst. Cent., Chapel Hill, N.C., 18-20 October, 2004.

Binkowski, F. S. and Shankar, U.: The regional particulate model, 1 , Model description and preliminary results, J. Geophys. Res., 100, 26191-26209, 1995.

Byun, D. and Schere, K.: Review of the governing equations, computation algorithms, and other components of the Models-3 Community Multiscale Air Quality (CMAQ) modeling system, Appl. Mech. Rev., 59, 51-77, 2006.

Chuang, C., Penner, J., Prospero, J., Grant, K., Rau, G., and Kawamoto, K.: Cloud susceptibility and the first aerosol indirect forcing: sensitivity to black carbon and aerosol concentrations, J. Geophys. Res., 107, AAC-10, doi:10.1029/2000JD000215, 2002.

Cotton, W., Pielke, R., Walko, G., Liston, G., Tremback, C., Jiang, H., McAnelly, R., Harrington, J., Nicholls, M., Carrio, G., and McFadden, J.: RAMS 2001: current status and future directions, Meteorol. Atmos. Phys., 82, 5-29, 2003.

Ding, F., Pal Arya, S., and Lin, Y.: Large-eddy simulations of the atmospheric boundary layer using a new subgrid-scale model-II. Weakly and moderately stable cases, Environ. Fluid Mech., 1, 49-69, 2001.

Eder, B. and Yu, S. C.: An evaluation of model performance of EPA models-3/CMAQ, Atmos. Environ., 40, 4811-4824, 2006.

Eder, B., Kang, D., Mathur, R., Pleim, J., Yu, S. C., Otte, T., and Pouliot., G.: A performance evaluation of the national air quality forecast capability for the summer of 2007, Atmos. Environ., 43 , 2312-2320, 2009.

Feng, S., Hu, Q., and Qian, W.: Quality control of daily meteorological data in China, 1951-2000: a new dataset, Int. J. Climatol., 24, 853-870, 2012.

Gao, J., Zhang, Y., Wang, S., Chi, F., and Chen, Y.: Study on the Characteristics and Formation of a Multi-Day Haze in October 2011 in Beijing, Res. Environ. Sci., 25, 1201-1207, 2012 (in Chinese).

Ghan, S. and Zaveri, R.: Parameterization of optical properties for hydrated internally mixed aerosol, J. Geophys. Res., 112, D10201, doi:10.1029/2006JD007927, 2007.

Gong, S. L.: A parameterization of sea-salt aerosol source function for sub- and super-micron particles, Global Biogeochem. Cy., 17, 8.1-8.7, doi:10.1029/2003GB002079, 2003.

Han, X., Zhang, M., Han, Z., Xin, J., and Liu, X.: Simulation of aerosol direct radiative forcing with RAMS-CMAQ in East Asia, Atmos. Environ., 45, 6576-6592, 2011.

Han, X., Zhang, M., Tao, J., Wang, L., Gao, J., Wang, S., and Chai, F.: Modeling aerosol impacts on atmospheric visibility in Beijing with RAMS-CMAQ, Atmos. Environ., 72, 177-191, 2013.

Han, Z., Ueda, H., Matsuda, K., Zhang, R., Arao, K., Kanai, Y., and Hasome, H.: Model study on particle size segregation and deposition during Asian dust events in March 2002, J. Geophys. Res., 109, D19205, doi:10.1029/2004JD004920, 2004.

Hao, J. and Wang, L.: Improving Urban Air Quality in China: Beijing Case Study, Air Waste Manage. Assoc., 62, 1298-1305, 2012.

Heald, C. L., Jacob, D. J., Park, R. J., Russell, L. M., Huebert, B. J., Seinfeld, J. H., Liao, H., and Weber, R. J.: A large organic aerosol source in the free troposphere missing from current models, Geophys. Res. Lett., 32, L18809, doi:10.1029/2005GL023831, 2005.

Henze, D. K. and Seinfeld, J. H.: Global secondary organic aerosol from isoprene oxidation, Geophys. Res. Lett., 33, L09812, doi:10.1029/2006GL025976, 2006.

Koch, D., Bond, T. C., Streets, D., Unger, N., and van der Werf, G. R.: Global impact of aerosols from particular source regions and sectors, J. Geophys. Res., 112, D02205, doi:10.1029/2005JD007024, 2007.

Kroll, J. H., Ng, N. L., Murphy, S. M., Flagan, R. C., and Seinfeld, J. H.: Secondary organic aerosol formation from isoprene photooxidation, Environ. Sci. Technol., 40, 1869-1877, 2006.

Li, W. J., Shao, L. Y., and Buseck, P. R.: Haze types in Beijing and the influence of agricultural biomass burning, Atmos. Chem Phys., 10, 8119-8130, doi:10.5194/acp-10-8119-2010, 2010.

Li, Z., Gu, X., Wang, L., Li, D., Xie, Y., Li, K., Dubovik, O., Schuster, G., Goloub, P., Zhang, Y., Li, L., Ma, Y., and Xu, H.: Aerosol physical and chemical properties retrieved from ground-based remote sensing measurements during heavy haze days in Beijing winter, Atmos. Chem. Phys., 13, 10171-10183, doi:10.5194/acp13-10171-2013, 2013.

Liu, X. G., Li, J., Qu, Y., Han, T., Hou, L., Gu, J., Chen, C., Yang, Y., Liu, X., Yang, T., Zhang, Y., Tian, H., and Hu, M.: Formation and evolution mechanism of regional haze: a case study in the megacity Beijing, China, Atmos. Chem. Phys., 13, 4501-4514, doi:10.5194/acp-13-4501-2013, 2013.

Lu, Z., Streets, D. G., Zhang, Q., Wang, S., Carmichael, G. R., Cheng, Y. F., Wei, C., Chin, M., Diehl, T., and Tan, Q.: Sulfur dioxide emissions in China and sulfur trends in East Asia since 
2000, Atmos. Chem. Phys., 10, 6311-6331, doi:10.5194/acp-106311-2010, 2010.

Lu, Z., Zhang, Q., and Streets, D. G.: Sulfur dioxide and primary carbonaceous aerosol emissions in China and India, 1996-2010, Atmos. Chem. Phys., 11, 9839-9864, doi:10.5194/acp-11-98392011, 2011.

Ma, J., Xu, X., Zhao, C., and Yan, P.: A review of atmospheric chemistry research in China: Photochemical smog, haze pollution, and gas-aerosol interactions, Adv. Atmos. Sci., 29, 10061026, 2010.

Mathur, R., Yu, S. C., Kang, D., and Schere, K. L.: Assessment of the winter-time performance of developmental particulate matter forecasts with the Eta-CMAQ modeling system, J. Geophys. Res., 113, D02303, doi:10.1029/2007JD008580, 2008.

Nenes, A., Pandis, S., and Pilinis, C.: Continued development and testing of a new thermodynamic aerosol module for urban and regional air quality models, Atmos. Environ., 33, 1553-1560, 1999.

Pruppacher, H. and Klett, J.: Microphysics of Clouds and Precipitation, Springer, New York, pp. 954, 1997.

Quan, J., Zhang, Q., He, H., Liu, J., Huang, M., and Jin, H.: Analysis of the formation of fog and haze in North China Plain (NCP), Atmos. Chem. Phys., 11, 8205-8214, doi:10.5194/acp-11-82052011, 2011.

Randerson, J. T., van der Werf, G. R., Giglio, L., Collatz, G. J., and Kasibhatla, P. S.: Global Fire Emissions Database, Version 2 (GFEDv2.1), Data set available on-line (http:// daac.ornl.gov/) from Oak Ridge National Laboratory Distributed Active Archive Center, Oak Ridge, Tennessee, USA, doi:10.3334/ORNLDAAC/849, 2007.

Sarwar, G., Luecken, D., Yarwood, G., Whitten, G., and Carter, W.: Impact of an updated carbon bond mechanism on predictions from the CMAQ modeling system: preliminary assessment, J. Appl. Meteorol. Clim., 47, 3-14, 2008.

Seinfeld, J. and Pandis, S.: Atmospheric Chemistry and Physics, Wiley, New York, USA, 1998.

Sun, Y., Zhuang, G., Tang, A., Wang, Y., and An, Z.: Chemical characteristics of $\mathrm{PM}_{2.5}$ and $\mathrm{PM}_{10}$ in Haze-Fog episodes in Beijing, Environ. Sci. Technol., 40, 3148-3155, 2006.

Tao, M., Chen, L., Su, L., and Tao, J.: Satellite observation of regional haze pollution over the North China Plain, J. Geophys. Res., 117, D12203, doi:10.1029/2012JD017915, 2012.

Wang, X., Sun, M., Yang, T., and Wang, Z.: Interdecadal change in frequency of dust-haze episodes in North China Plain, Clim. Environ. Res., 18, 165-170, 2013 (in Chinese).

Wang, Y., Zhuang, G., Sun, Y., and An, Z.: The variation of characteristics and formation mechanisms of aerosols in dust, haze, and clear days in Beijing, Atmos. Environ., 40, 6579-6591, 2006.

Wu, D., Bi, X., Deng, X., Li, F., and Tan, H.: Effect of atmospheric haze on the deterioration of visibility over the Pearl River Delta, Acta Geogr. Sin., 21, 215-223, 2007 (in Chinese).
Yu, S. C., Eder, B., Dennis, R., Chu, S. H., and Schwartz, S.: New unbiased symmetric metrics for evaluation of air quality models, Atmos. Sci. Lett., 7, 26-34, 2006.

Yu, S. C., Bhave, P. V., Dennis, R. L., and Mathur, R.: Seasonal and regional variations of primary and secondary organic aerosols over the continental United States: semi-empirical estimates and model evaluation, Environ. Sci. Technol., 41, 4690-4697, 2007.

Yu, S., Mathur, R., Pleim, J., Wong, D., Gilliam, R., Alapaty, K., Zhao, C., and Liu, X.: Aerosol indirect effect on the grid-scale clouds in the two-way coupled WRF-CMAQ: model description, development, evaluation and regional analysis, Atmos. Chem. Phys. Discuss., 13, 25649-25739, doi:10.5194/acpd-13-256492013, 2013.

Yu, X., Zhu, B., Yin, Y., Yang, J., Li, Y., and Bu, X.: A comparative analysis of aerosol properties in dust and haze-fog days in a Chinese urban region, Atmos. Res., 99, 241-247, 2011.

Zhang, A., Qi, Q., Jiang, L., Zhou, F., and Wang, J.: Population exposure to $\mathrm{PM}_{2.5}$ in the urban aera of Beijing, PloS one, 8, e63486, doi:10.1371/journal.pone.0063486, 2013.

Zhang, J., Miao, H., Ouyang, Z., and Wang, X.: Ambient air quality trends and driving factor analysis since 1980's in Beijing, Acta Sci. Circumstantiae, 26, 1886-1892, 2006 (in Chinese).

Zhang, J. K., Sun, Y., Liu, Z. R., Ji, D. S., Hu, B., Liu, Q., and Wang, Y. S.: Characterization of submicron aerosols during a month of serious pollution in Beijing, 2013, Atmos. Chem. Phys., 14, 2887-2903, doi:10.5194/acp-14-2887-2014, 2014.

Zhang, J. P., Zhu, T., Zhang, Q. H., Li, C. C., Shu, H. L., Ying, Y., Dai, Z. P., Wang, X., Liu, X. Y., Liang, A. M., Shen, H. X., and Yi, B. Q.: The impact of circulation patterns on regional transport pathways and air quality over Beijing and its surroundings, Atmos. Chem. Phys., 12, 5031-5053, doi:10.5194/acp-12-50312012, 2012.

Zhang, M., Xu, Y., Zhang, R., and Han, Z.: Emission and concentration distribution of black carbon aerosol in East Asia during springtime, Chin. J. Geophys., 48, 55-61, 2005.

Zhang, M., Uno, I., Zhang, R., Han, Z.,Wang, Z., and Pu, Y.: Evaluation of the Models-3 Community Multi-scale Air Quality (CMAQ) modeling system with observations obtained during the TRACE-P experiment: comparison of ozone and its related species, Atmos. Environ., 40, 4874-4882, 2006.

Zhang, M., Gao, L., Ge, C., and Xu, Y.: Simulation of nitrate aerosol concentrations over East Asia with the model system RAMSCMAQ, Tellus B, 59, 372-380, 2007.

Zhao, P., Zhang, X., Xu, X., and Zhao, X.: Long-term visibility trends and characteristics in the region of Beijing, Tianjin, and Hebei, China, Atmos. Res., 101, 711-718, 2011.

Zhao, X. J., Zhao, P. S., Xu, J., Meng, W., Pu, W. W., Dong, F., He, D., and Shi, Q. F.: Analysis of a winter regional haze event and its formation mechanism in the North China Plain, Atmos. Chem. Phys., 13, 5685-5696, doi:10.5194/acp-13-5685-2013, 2013. 